\title{
Assessing regional scale predictions of aerosols, marine stratocumulus, and their interactions during VOCALS-REx using WRF-Chem
}

\author{
Q. Yang ${ }^{1}$, W. I. Gustafson Jr. ${ }^{1}$, J. D. Fast ${ }^{1}$, H. Wang ${ }^{1}$, R. C. Easter ${ }^{1}$, H. Morrison ${ }^{2}$, Y.-N. Lee ${ }^{3}$, E. G. Chapman ${ }^{1}$, \\ S. N. Spak ${ }^{4}$, and M. A. Mena-Carrasco ${ }^{5}$ \\ ${ }^{1}$ Pacific Northwest National Laboratory, Richland, WA, USA \\ ${ }^{2}$ National Center for Atmospheric Research, Boulder, CO, USA \\ ${ }^{3}$ Brookhaven National Laboratory, Upton, New York, USA \\ ${ }^{4}$ Public Policy Center, University of Iowa, Iowa City, IA, USA \\ ${ }^{5}$ Center for Sustainability Research, Universidad Andrés Bello, Santiago, Chile
}

Received: 22 July 2011 - Published in Atmos. Chem. Phys. Discuss.: 11 August 2011

Revised: 3 November 2011 - Accepted: 8 November 2011 - Published: 2 December 2011

\begin{abstract}
This study assesses the ability of the recent chemistry version (v3.3) of the Weather Research and Forecasting (WRF-Chem) model to simulate boundary layer structure, aerosols, stratocumulus clouds, and energy fluxes over the Southeast Pacific Ocean. Measurements from the VAMOS Ocean-Cloud-Atmosphere-Land Study Regional Experiment (VOCALS-REx) and satellite retrievals (i.e., products from the MODerate resolution Imaging Spectroradiometer (MODIS), Clouds and Earth's Radiant Energy System (CERES), and GOES-10) are used for this assessment. The Morrison double-moment microphysics scheme is newly coupled with interactive aerosols in the model. The 31day (15 October-16 November 2008) WRF-Chem simulation with aerosol-cloud interactions (AERO hereafter) is also compared to a simulation (MET hereafter) with fixed cloud droplet number concentrations in the microphysics scheme and simplified cloud and aerosol treatments in the radiation scheme. The well-simulated aerosol quantities (aerosol number, mass composition and optical properties), and the inclusion of full aerosol-cloud couplings lead to significant improvements in many features of the simulated stratocumulus clouds: cloud optical properties and microphysical properties such as cloud top effective radius, cloud water path, and cloud optical thickness. In addition to accounting for the aerosol direct and semi-direct effects, these improvements feed back to the simulation of boundary-layer characteristics and energy budgets. Particularly, inclusion of interac-
\end{abstract}

tive aerosols in AERO strengthens the temperature and humidity gradients within the capping inversion layer and lowers the marine boundary layer (MBL) depth by $130 \mathrm{~m}$ from that of the MET simulation. These differences are associated with weaker entrainment and stronger mean subsidence at the top of the MBL in AERO. Mean top-of-atmosphere outgoing shortwave fluxes, surface latent heat, and surface downwelling longwave fluxes are in better agreement with observations in AERO, compared to the MET simulation. Nevertheless, biases in some of the simulated meteorological quantities (e.g., MBL temperature and humidity) and aerosol quantities (e.g., underestimations of accumulation mode aerosol number) might affect simulated stratocumulus and energy fluxes over the Southeastern Pacific, and require further investigation. The well-simulated timing and outflow patterns of polluted and clean episodes demonstrate the model's ability to capture daily/synoptic scale variations of aerosol and cloud properties, and suggest that the model is suitable for studying atmospheric processes associated with pollution outflow over the ocean. The overall performance of the regional model in simulating mesoscale clouds and boundary layer properties is encouraging and suggests that reproducing gradients of aerosol and cloud droplet concentrations and coupling cloud-aerosol-radiation processes are important when simulating marine stratocumulus over the Southeast Pacific.

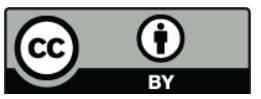

Correspondence to: Q. Yang

(qing.yang@pnnl.gov)

Published by Copernicus Publications on behalf of the European Geosciences Union. 


\section{Introduction}

Marine stratocumuli play an important role in radiation and hydrological budgets, particularly along the eastern edges of oceans, such as over the Southeast Pacific Ocean (SEP) (Stevens et al., 2005; Stevens and Feingold, 2009). These clouds are bright compared to the dark ocean surface and result in much more shortwave radiation scattered back to space. Their effective temperature is comparable to that of the ocean surface, so the emitted longwave radiation imposes little compensating effect. Therefore, properly representing these clouds in climate models is important. However, marine stratocumuli are notoriously difficult to model accurately. The recent Preliminary VOCALS model Assessment (PreVOCA) (Wyant et al., 2010) showed a wide range in behavior among models in representing such clouds. One reason for this difference is the simplified treatments of aerosols used by most models, for example, assuming a constant background aerosol concentration or cloud droplet number concentration in the microphysics modules. In reality, strong gradients in aerosol number and composition exist as one progresses westward from the coast towards the open ocean. These gradients result in cloud condensation nuclei $(\mathrm{CCN})$ gradients and lead to differing cloud characteristics as well.

Reproducing CCN gradients and including coupled cloudaerosol-radiation processes are important to properly simulate the marine stratocumulus over the SEP. This paper shows the improvement gained in using an interactive aerosol-cloud-radiation module in the chemistry version of the Weather Research and Forecasting (WRF-Chem) model (Grell et al., 2005; Fast et al., 2006). Specifically, a new coupling between the double-moment Morrison microphysics scheme (Morrison et al., 2005, 2009) and the aerosol modules is used; we implemented this coupling in the April 2011 v3.3 release of WRF-Chem. The VAMOS Ocean-CloudAtmosphere-Land Study Regional Experiment (VOCALSREx) was a field campaign during October and November 2008 designed to improve the scientific understanding of model simulations and predictions of the coupled climate system over the SEP (Wood et al., 2011b). The campaign provided extensive measurements for evaluating the capability of our model with the aforementioned new coupling in predicting aerosol and marine stratus clouds over this region.

A recent modeling exercise by Abel et al. (2010) using the UK Met Office Unified Model (MetUM) is parallel to this model evaluation study. MetUM simulated a good representation of synoptically induced variability in cloud cover and boundary layer depth during the VOCALS-REx (Abel et al., 2010). However, the exclusion of cloud-aerosol interactions and the model's relatively simple parameterization of cloud-microphysical effects (Toniazzo et al., 2011) are likely to preclude better agreement with field observations.

Aerosol-cloud interactions are important to the variability of marine stratus. Aerosols can impact radiative fluxes di- rectly through absorption and scattering (the direct effect), semi-directly through the impact of aerosol absorption on atmospheric heating and stability (semi-direct effect), and indirectly through their impact on liquid clouds via the socalled indirect effects (Twomey, 1977; Albrecht, 1989). The first indirect effect is the change in cloud albedo due to the change in cloud droplet number and radius. The second indirect effect (also known as the "cloud lifetime effect") is the change in cloud lifetime and precipitation due to change in cloud droplet number; the importance of this effect on radiative forcing is evident in shallow marine status (Stevens and Feingold, 2009). By changing warm-rain processes in marine stratocumulus clouds, aerosols can alter cloud cellular structures and boundary-layer mesoscale circulations in ways that are much more complicated than traditionally depicted by conceptual models of the indirect effects (Steven et al., 2005; Wang and Feingold, 2009a, b). The emerging importance and complexity of aerosol-cloud-precipitation interactions in shallow marine status is gaining recognition by the scientific community (Stevens and Feingold, 2009). These aerosol-cloud interactions and associated dynamical feedbacks are particularly important over the SEP.

The strong gradients of anthropogenic and natural aerosols in the marine boundary layer (MBL), make the SEP an ideal location for studying the response of shallow marine clouds to aerosol perturbations. Along the coast of Chile and Peru, copper smelters, power plants, and oil refineries emit large amounts of oxidized sulfur (sulfur dioxide $\left(\mathrm{SO}_{2}\right)+$ sulfate) (Huneeus et al., 2006). Other continental sources include volcanic, biomass burning, biogenic, and dust emissions. Associated with mid-latitude synoptic-scale disturbances, easterly flow subsides down the subtropical Andes, and brings the emitted trace gases and particles over the continent to the stratus deck (Huneeus et al., 2006). These continental pollutants, both primary and secondary, are then mixed with trace gases and particles from oceanic emissions. Marine sources of primary aerosols include sea-salt and organic compounds from sea spray and bubble bursting (Russell et al., 2010), and a source of secondary aerosols is the oxidation of dimethyl sulfide (DMS) to sulfate and methanesulfonic acid (MSA). Detailed understanding of the aerosol-cloud interactions (e.g., the transition from closed to open cellular convection) and properly reproducing the climate impact of these clouds remain a challenge for current climate modeling.

This study evaluates simulated aerosols and cloud fields in the WRF-Chem model with the newly implemented coupling between the double-moment Morrison microphysics scheme and aerosols, and is a necessary first step before progressing to further studies on multiple aerosol-cloud equilibrium regimes and the sensitivity of predicted SEP cloud fields to model horizontal grid resolution. A simulation with spatially and temporally varying aerosols and aerosol-cloud-radiation couplings is compared against another with a fixed cloud droplet number concentration in the microphysics scheme 
and simplified cloud and aerosol treatments in the radiation scheme. A description of the model and observational data is provided in Sect. 2. In Sect. 3, we first discuss the characteristics of the simulated marine boundary layer (Sect. 3.1), then evaluate simulated aerosol (Sect. 3.2), cloud optical properties (Sect. 3.3) and cloud macro structures (Sect. 3.4). The domain-average top-of-atmosphere (TOA) shortwave (SW) fluxes and longitudinal and diurnal variations in surface energy fluxes are discussed in Sect. 3.5. Model representations of longitudinal and vertical variations of drizzle are shown in Sect. 3.6. The discussion and summary of the evaluation results are presented in Sects. 4 and 5, respectively.

\section{Model description and observational data}

\subsection{WRF-Chem}

WRF-Chem is a widely used regional model employed operationally for air quality (e.g., Zhang et al., 2010) and tracer forecasting (http://www-frd.fsl.noaa.gov/aq/wrf/), detailed aerosol process studies (e.g., Fast et al., 2009), and regional climate studies involving aerosols (e.g., Qian et al., 2009). It includes full online interactions between aerosols, radiation, and clouds for the direct, semi-direct, and first and second indirect effects as described in Fast et al. (2006), Chapman et al. (2009), and Gustafson et al. (2007). Past research included aerosol indirect effects only through the Lin microphysics scheme. This has now been complemented in WRF-Chem v3.3 with the additional option to use the Morrison microphysics scheme. The simulations presented in this study were performed by using the code as implemented in WRF-Chem v3.2.1, which was then released to the public in v3.3.

For comparison purposes, two simulations were conducted: one with aerosol-cloud interactions (referred to as AERO) and the other with aerosol and chemistry modules turned off and droplet number prescribed (referred to as MET). Table 1 shows the model configuration used for the simulations in this study. The configuration is representative for simulations involving full aerosol-climate effects. The Model for Simulating Aerosol Interactions and Chemistry (MOSAIC) (Zaveri et al., 2008) is implemented with a sectional approach where the size distributions for both unactivated/interstitial and activated aerosols are represented with 8 bins whose lower and upper dry diameters are listed in Table 2. What is new compared to previous published studies using the MOSAIC aerosol module is the inclusion of DMS chemistry as a source of atmospheric $\mathrm{SO}_{2}$ and sulfuric acid $\left(\mathrm{H}_{2} \mathrm{SO}_{4}\right)$. In this study, a correction has been made to the reaction rate for the decomposition of methanesulfonyl $\left(\mathrm{CH}_{3} \mathrm{SO}_{2}\right)$ radicals into $\mathrm{SO}_{2}$, which has been incorporated into WRF-Chem v3.3. Secondary organic aerosol formation (Shrivastava et al., 2010) is not included in the simulations presented here to reduce the overall computational expense and, as shown later, organic aerosols are a relatively small fraction of the total aerosol mass over the SEP. Subgrid cumulus parameterization was turned off for the simulations in this study due to the following reasons. The predominant clouds during VOCALS-REx were marine stratocumulus, which are generally not treated well by cumulus parameterizations. In a short 9-day test run using the Kain-Fritsch cumulus scheme, there was no apparent improvement in simulated cloud features and precipitation. Also, the cumulus schemes currently in WRF-Chem have not been coupled with interactive aerosol.

The Morrison microphysics scheme predicts changes of number and mass mixing ratios of cloud water, cloud ice, snow, rain, and graupel/hail associated with the following microphysical processes: autoconversion (transfer of mass and number concentration from the cloud ice and droplet classes to snow and rain due to coalescence and diffusional growth), collection between hydrometeor species, melting/freezing, and ice multiplication (transfer of mass from snow to ice) (Morrison et al., 2005). Cloud droplets are represented by a gamma distribution and the size distributions of all other hydrometeor species are assumed to follow an exponential function (Morrison et al., 2009). When interactive aerosols are not included, a constant droplet concentration is assumed. In the MET simulation, within the Morrison double-moment microphysics scheme cloud water mixing ratio is predicted but cloud droplet number concentration is prescribed as a constant value $\left(250 \mathrm{~cm}^{-3}\right)$; aerosols have no impact on cloud microphysics. However, this constant droplet number affects the autoconversion of cloud water to rainwater and thus affects the rainwater and raindrop number concentrations. Another difference between AERO and MET is that in the MET simulation, the predicted droplet sizes and number concentrations from the microphysics scheme do not feed into shortwave radiation scheme, where the predicted cloud water and a constant effective radius are used. The activation and more complex couplings with interactive aerosols are described as follows. Activation of aerosols to cloud droplets is based on the maximum supersaturation, which is diagnosed using a combination of the resolved vertical velocity and turbulent motions, in combination with the internally mixed aerosol properties within each size bin (Chapman et al., 2009). Aerosol-cloud interactions in warm clouds occur in two ways: aerosols affect clouds (activation of $\mathrm{CCN}$ is the main source of cloud droplets) and clouds affect aerosols (wet removal is the main sink of submicron particles and cloud chemistry is a major source of sulfate). The interactions between clouds and shortwave radiation for the first indirect effect are implemented by linking the predicted cloud droplet number from the Morrison microphysics scheme with the Goddard shortwave radiative scheme. The second indirect effect is handled directly by the microphysics scheme for warm-rain processes, where the number of activated particles affects precipitation and cloud 
Table 1. Primary model configuration settings.

\begin{tabular}{ll}
\hline Atmospheric Process & WRF Option \\
\hline Tracer advection & Monotonic \\
Longwave radiation & RRTM \\
Shortwave radiation & Goddard \\
Surface layer & MM5 similarity theory \\
Land surface & Noah \\
Boundary layer & YSU \\
Deep and shallow cumulus clouds & Turned off \\
Cloud microphysics & Morrison \\
Gas phase chemistry & CBM-Z with DMS reactions \\
Aerosol chemistry & 8-bin MOSAIC (for AERO) \\
Photolysis & Madronich (for AERO) \\
Aerosol direct \& semi-direct effects & Turned on (for AERO) \\
Aqueous chemistry, wet scavenging, and cloud-aerosol interactions & Turned on (for AERO) \\
\hline
\end{tabular}

Table 2. Particle dry-diameter range for the eight MOSAIC aerosol size bins employed in this study.

\begin{tabular}{lrr}
\hline Bin & $\begin{array}{c}\text { Lower Diameter } \\
(\mu \mathrm{m})\end{array}$ & $\begin{array}{c}\text { Upper Diameter } \\
(\mu \mathrm{m})\end{array}$ \\
\hline 1 & 0.0390625 & 0.078125 \\
2 & 0.078125 & 0.15625 \\
3 & 0.15625 & 0.3125 \\
4 & 0.3125 & 0.625 \\
5 & 0.625 & 1.25 \\
6 & 1.25 & 2.5 \\
7 & 2.5 & 5.0 \\
8 & 5.0 & 10.0 \\
\hline
\end{tabular}

lifetime. Aerosol effects on longwave radiation are not included in this study, but have also been recently incorporated into WRF v3.3 as described in Zhao et al. (2010).

Advection of scalar quantities (e.g., aerosol and hydrometeor number mixing ratios) was found to be critical to the performance of a double-moment microphysics scheme incorporated into WRF when simulating stratocumulus clouds with interactive $\mathrm{CCN}$, particularly near strong gradients (Wang et al., 2009); therefore, we employ the monotonic advection scheme for model scalars and chemical species for better accuracy in advection even though it is more computationally expensive.

Simulated evolution of the MBL and stratocumulus clouds will be highly dependent upon the Planetary Boundary Layer (PBL) parameterization with our $9 \mathrm{~km}$ horizontal grid spacing. In this study, the YSU scheme (Hong et al., 2006) is used, which employs nonlocal-K (vertical diffusion coefficient) mixing for momentum, entrainment of heat and momentum fluxes at the PBL top, a local-K approach for atmospheric diffusion above the mixed layer, and a critical bulk Richardson number of zero for the PBL top.
The model domain covers part of the northern Chilean and southern Peruvian coasts and the nearby Southeast Pacific, roughly $63^{\circ} \mathrm{W}-93^{\circ} \mathrm{W}$ in longitude and $11^{\circ} \mathrm{S}-36^{\circ} \mathrm{S}$ in latitude. Throughout the paper, two regions, the "coastal region" and the "remote region", are defined. The two regions are separated by the $78^{\circ} \mathrm{W}$ meridian with the west (remote region) characterized by remote marine aerosol conditions and the east (coastal region) characterized by anthropogenic influences mixed with the maritime background. From the surface to $50 \mathrm{hPa}$, the model has 64 vertical layers, and the layer thickness increases from $\sim 30 \mathrm{~m}$ at the surface to $\sim 50 \mathrm{~m}$ at $1 \mathrm{~km}$ and $\sim 90 \mathrm{~m}$ at $2 \mathrm{~km}$ above the ocean surface. The horizontal grid spacing is $9 \mathrm{~km}$. Excluding five-days of model spin-up, the simulation period is from 00:00 UTC 15 October 2008 to 00:00 UTC 16 November 2008. Initial conditions, boundary conditions, and time dependent sea surface temperatures (SSTs) for meteorology were obtained from the Global Forecast System (GFS) model output with a 0.5-degree grid spacing, while the Model for Ozone and Related chemical Tracers (MOZART) provided the initial and boundary conditions for trace gases and aerosols. Emissions used for the AERO simulation are as follows. Coarse and fine mode seasalt emissions are based on Gong et al. (1997) and Monahan et al. (1986), which neglect sea-salt production through breaking waves, while ultrafine sea-salt emissions follow Clarke et al. (2006). Sea-salt particles are treated as $\mathrm{NaCl}$ in the model. DMS emissions are calculated using a simplified Nightingale et al. (2000) scheme with constant SST and a geographically uniform ocean surface DMS concentration of $2.8 \mathrm{~m} \mathrm{~mol}^{-1}$ as specified in the VOCA Modeling Experiment Specification (http://www.atmos.washington.edu/ $\sim$ mwyant/vocals/model/VOCA_Model_Spec.htm). Terrestrial biogenic emissions are calculated using the MEGAN (Guenther et al., 2006) emission module in WRF-Chem. The VOCA Emission inventory compiled for VOCA supplied anthropogenic (both point and area source emissions are 
included) and volcanic emissions. Emissions of carbon monoxide $(\mathrm{CO})$, oxides of nitrogen $\left(\mathrm{NO}_{\mathrm{x}}\right), \mathrm{SO}_{2}$, ammonia $\left(\mathrm{NH}_{3}\right)$, black carbon $(\mathrm{BC})$, organic carbon $(\mathrm{OC})$, particles $10 \mu \mathrm{m}$ or less in diameter $\left(\mathrm{PM}_{10}\right)$, particles $2.5 \mu \mathrm{m}$ or less in diameter $\left(\mathrm{PM}_{2.5}\right)$, and volatile organic compounds (VOCs) are included in the VOCA inventory; oceanic $\mathrm{NH}_{3}$ emissions are not included. Biomass burning emissions (CO, $\mathrm{NO}_{\mathrm{x}}, \mathrm{SO}_{2}, \mathrm{NH}_{3}, \mathrm{VOCs}, \mathrm{OC}, \mathrm{BC}$, and $\mathrm{PM}_{2.5}$ ) are based on the MODerate resolution Imaging Spectroradiometer (MODIS) fire counts and combustion estimates that depend on location-specific vegetation type (Wiedinmyer et al., 2011). Windblown dust emissions are based on the Shaw et al. (2008) formulation.

\subsection{Observational data}

A wide range of meteorological, trace gas, and aerosol measurements were collected during VOCALS-REx as described in Wood et al. (2011b). The NCAR C-130 aircraft and the NOAA Ronald H. Brown research vessel (hereafter RB) were selected as the main measurement platforms for the model evaluation in this study due to two main reasons: (1) both the $\mathrm{C}-130$ and $\mathrm{RB}$ provided measurements farther into the remote ocean region $\left(\sim 88^{\circ} \mathrm{W}\right)$ of the model domain; this extended longitudinal data coverage is necessary for the purpose of contrasting different aerosol and cloud characteristics over polluted and clean environments; and (2) the RB provided energy fluxes, DMS ocean-to-air transfer velocity, and other near-surface measurements that are important to the model assessment, and those measurements are complementary to measurements obtained on the flight platforms. The selection of the RB as one of the two main platforms leads to the division of the model domain into two regions (remote and costal regions) since the RB sampled more intensively around $\sim 85^{\circ} \mathrm{W}$ and $\sim 75^{\circ} \mathrm{W}$. Within the domain, there are about twice as many samples over the coastal region compared to the remote region from both the $\mathrm{C}-130$ and RB platforms during the VOCALS-REx. Here we briefly describe the observations that are employed in this modeling study. Detailed descriptions of the instruments can be found elsewhere (e.g., Allen et al., 2011; Wood et al., 2011a; Yang et al., 2011).

\subsubsection{Aerosol number and mass concentrations}

During the VOCALS-REx, a Particle Measurement System (PMS) Passive Cavity Aerosol Spectrometer Probe (PCASP) measured accumulation mode aerosol particles (dry diameter $0.117-2.94 \mu \mathrm{m}$ ) on the aircraft. For the purpose of matching aerosol particle sizes between PCASP measurements and model simulations, this study uses only measured aerosol particle concentrations with diameters of $0.156-2.69 \mu \mathrm{m}$.

Aerosol Mass Spectrometers (AMS) described below measured non-refractory, non-sea-salt mass loading of aerosol sulfate, ammonium, nitrate, and particulate organic matter (OM). The AMS instruments on the C-130 (DeCarlo et al., 2006) and the United Kingdom (UK) British Aerospace-146 (BAe-146) aircrafts measured aerosol components aloft for particle sizes (vacuum aerodynamic diameter) between 0.05 and $0.5 \mu \mathrm{m}$ and the AMS on the G-1 aircraft (Kleinman et al., 2011) measured aerosol compositions in the $0.06-0.6 \mu \mathrm{m}$ diameter range. The AMS (Hawkins et al., 2010) onboard the RB research vessel provided surfacelevel particle measurements in the submicron range. The BAe-146 AMS dataset retrieved with collection efficiency of 1 was used, and the detailed justification can be found in Allen et al. (2011).

The sub- and supermicron chloride and sodium aerosols were sampled by two-stage multi-jet cascade impactors (CIS) on the RB, with $50 \%$ aerodynamic cutoff diameters of 1.1 and $10 \mu \mathrm{m}$ at $60 \%$ relative humidity. Submicron chloride and sodium were also sampled by a Particle Into Liquid Sampler (PILS) on the G-1 aircraft, with a sampled particle size range of $0.06-1.5 \mu \mathrm{m}$ at ambient humidity. The samples obtained with both the CIS and PILS were analyzed using ion chromatography. Corresponding modeled aerosol concentrations were obtained by first converting the measured particle wet-diameter size range to a dry-diameter size range (using the model's aerosol hygroscopicity), and then integrating the model's aerosol size distribution over this dry-diameter range. For model size bins partially included in the sampling range, a local quadratic fit between logarithmic diameter and mass in adjacent bins was used to estimate the mass in a partial bin.

\subsubsection{Cloud droplet sizing data, precipitation sizing data and cloud heights}

Cloud droplet sizing data measured by a PMS Cloud Droplet Probe (CDP) were available for 12 out of the 14 C-130 flights. This probe measures droplets in diameters of $1-$ $48 \mu \mathrm{m}$.

Precipitation sizing data obtained by PMS 2D-cloud (2DC) probes on the $\mathrm{C}-130$ and $\mathrm{BAe}-146$ were used to derive rain rates. The $2 \mathrm{D}-\mathrm{C}$ probes on the $\mathrm{C}-130$ and $\mathrm{BAe}-146$ measured droplet spectra within $62.5-1587.5 \mu \mathrm{m}$ and $37.5-812.5 \mu \mathrm{m}$ diameter ranges, respectively, with $25 \mu \mathrm{m}$ resolution. Note that excluding smaller size raindrops $(<62.5 \mu \mathrm{m}$ and $<37.5$ for the C-130 and BAe-146, respectively) could lead to a slight underestimation of the derived rain rates. In calculating rain rates from the measured droplet size distributions, relationships between fall velocities and raindrop diameters were based on Rogers and Yau (1989). Rain rates derived from the 2D-C measurements were then averaged for each $120 \mathrm{~s}$ flight leg segment with constant heading and elevation.

Cloud top and cloud base height retrievals were from measurements by the Wyoming cloud radar (WCR) and an upward-pointing lidar (WCL) aboard the C-130 aircraft, respectively. Measurements on the C-130 mostly rely on the retrieved cloud heights and flight elevations to determine 
whether measurements are within the MBL. For the G-1 and BAe-146, a combination of the flight elevation, relative humidity (or difference in temperature and dew point), and liquid water content measurements were used to determine whether the measurements are within the MBL. The same rules are also applied to the $\mathrm{C}-130$ when cloud height data are not available.

\subsubsection{Satellite data}

MODIS aerosol and cloud products (Level II Collection 5) were also used to evaluate the WRF-Chem simulations. Comparing with ground-based AERONET observations, Collection 5 MODIS aerosol optical depth (AOD) is within the expected accuracy of $\pm(0.03+0.05 \tau)$ for more than $60 \%$ of the time over the ocean, where $\tau$ is the AOD value (Remer et al., 2008). Both Terra and Aqua satellites have MODIS sensors aboard; however, according to Remer et al. (2008) Terra AOD has an unexpected and unexplained higher value over the ocean. Therefore, we only used MODIS aerosol products from Aqua. To be consistent, we present cloud products from Aqua in Fig. 7, although the related statistics are included in Table 5 for both Aqua and Terra satellites. In addition, we employed the low-cloud cover products retrieved from the GOES-10 channel 4 infrared radiances as described in Abel et al. (2010), available on a $0.5^{\circ} \times 0.5^{\circ}$ grid, and outgoing shortwave (SW) fluxes measured by the Clouds and the Earth's Radiant Energy System (CERES) aboard Terra (Loeb et al., 2005).

\section{Model results evaluated against observations}

In this section, model simulations are evaluated against measurements from VOCALS-REx and satellite retrievals for the period from 00:00 UTC 15 October 2008 to 00:00 UTC 16 November 2008. Comparisons with aircraft- and shipbased measurements used coincident data whereby model data were interpolated to the time and location of each measurement datum. Basic statistics, i.e., mean, standard deviation, and median, provided in Tables 3-7 are based on measurements from all available flights and cruises and their corresponding coincident model predictions during the 31-day period for the coastal and remote regions, and for the entire domain. MODIS retrievals were first gridded to the model domain. Then, both the gridded satellite data and the coincident model predictions were averaged over the entire study period for the statistics shown in Tables 3-7.

\subsection{Boundary layer structure}

Since marine stratocumulus clouds are sensitive to boundary layer conditions, we first evaluate simulated vertical profiles of virtual potential temperature $\left(\theta_{\mathrm{v}}\right)$ and water vapor mixing ratio $\left(q_{\mathrm{v}}\right)$ with those observed by $\mathrm{RB}$ radiosondes and BAe146 dropsondes (Fig. 1 and Table 3). The observed MBL is

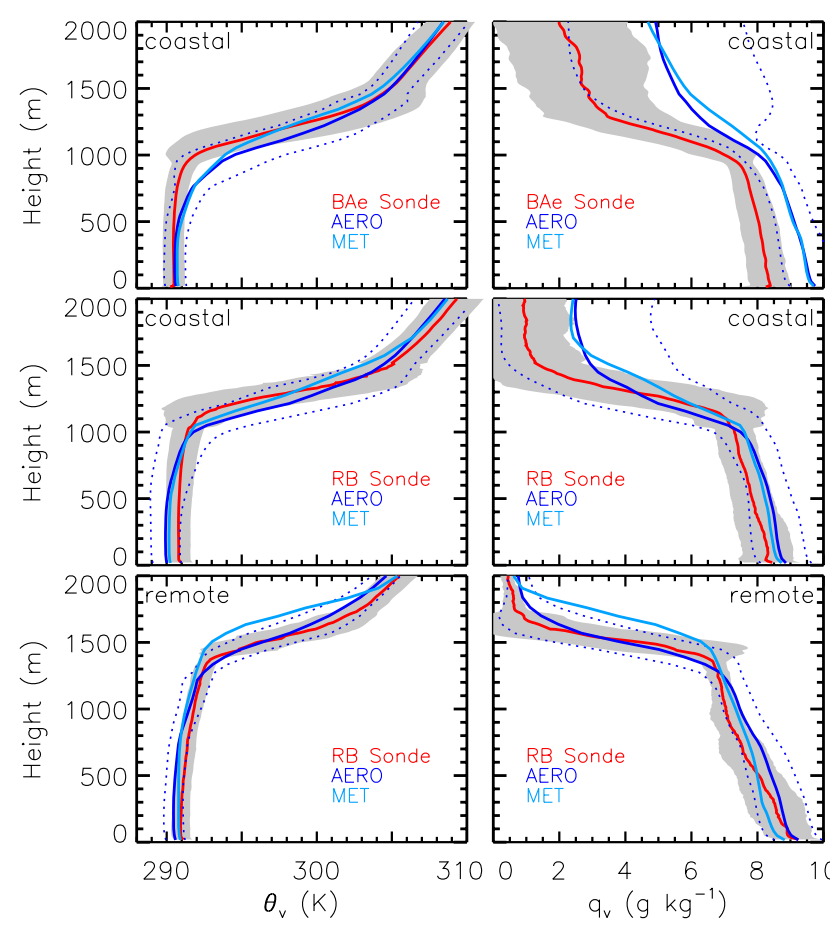

Fig. 1. Vertical profiles of virtual potential temperature $\left(\theta_{\mathrm{V}}\right)$ and water vapor mixing ratio $\left(q_{\mathrm{v}}\right)$ measured by radiosondes released from the RB ship (red) and those from AERO (blue) and MET (light blue) simulations. The shaded area represents $\pm 1 \sigma$ of the observations. The dash blue lines also indicate the $\pm 1 \sigma$ of the AERO simulations. Numbers of observational profiles used for the averaging are 31,54 , and 23 for panels in top, middle, and bottom rows, respectively.

more well-mixed over the coastal region than over the remote marine region. As evident in observed profiles over the remote region, there is more frequent decoupling (Zuidema et al., 2009) within the MBL over the remote region that separates the well-mixed cloud layer from the subcloud layer. The coastal region has a stronger temperature inversion with a $10-12 \mathrm{~K}$ increase in $\theta_{\mathrm{v}}$ within inversion layers (also see Table 3). The mean observed humidity and temperature in the MBL over the coastal and the remote regions, however, are not statistically different (at $98 \%$ confidence level) between the two regions.

Differences between AERO and MET in mean profiles of $\theta_{\mathrm{v}}$ and $q_{\mathrm{v}}$ are small, in general, except within the simulated inversion layer. In the coastal MBL, mean temperatures in the MBL from both simulations have small negative $(-0.6 \mathrm{~K}$ for AERO and $-0.9 \mathrm{~K}$ for MET) and positive biases $(0.6 \mathrm{~K}$ for AERO and $0.8 \mathrm{~K}$ for MET) compared to radiosondes and dropsondes, respectively. The positive bias in mean temperature compared to dropsondes originates from biases in the upper MBL where the mean simulated temperature deviated from observed well-mixed values (Fig. 1). Over the coastal region, the simulated $q_{\mathrm{v}}$ values 
Table 3. Observed and simulated MBL temperature and humidity, 10-m wind speed, SST, and boundary layer height.

\begin{tabular}{|c|c|c|c|c|}
\hline $\begin{array}{l}\text { Variable } \\
\text { (Units) }\end{array}$ & $\begin{array}{l}\text { Platform/ } \\
\text { Simulations }\end{array}$ & $\begin{array}{r}\text { Coastal region }^{\mathrm{a}} \\
\text { Mean/Std }\end{array}$ & $\begin{array}{r}\text { Remote region }^{\mathrm{a}} \\
\text { Mean/Std }\end{array}$ & $\begin{array}{r}\text { Both regions } \\
\text { Mean/Std }\end{array}$ \\
\hline \multicolumn{5}{|c|}{ Temperature, humidity, and MBLH ${ }^{\mathrm{d}, \mathrm{e}}$} \\
\hline \multirow{6}{*}{$\theta_{\mathrm{V}}(\mathrm{K})^{\mathrm{b}}$} & $\mathrm{RB}$ & $290.9 / 0.9$ & $291.2 / 0.6$ & $291.0 / 0.8$ \\
\hline & AERO & $290.3 / 1.2$ & $290.7 / 0.6$ & $290.4 / 1.1$ \\
\hline & MET & $290.0 / 1.1$ & $290.9 / 0.6$ & 290.6/1.0 \\
\hline & BAe-146 & $290.6 / 0.8$ & - & - \\
\hline & AERO & 291.3/1.2 & - & - \\
\hline & MET & $291.4 / 1.0$ & - & - \\
\hline \multirow{6}{*}{$\begin{array}{l}q_{\mathrm{v}} \\
\left(\mathrm{g} \mathrm{kg}^{-1}\right)^{\mathrm{b}}\end{array}$} & $\mathrm{RB}$ & $7.9 / 0.7$ & $8.1 / 0.7$ & $7.9 / 0.7$ \\
\hline & AERO & $8.3 / 0.7$ & $8.4 / 0.7$ & $8.4 / 0.7$ \\
\hline & MET & $8.2 / 0.8$ & $8.0 / 0.6$ & $8.2 / 0.7$ \\
\hline & BAe-146 & $8.0 / 0.6$ & - & - \\
\hline & AERO & $9.1 / 0.7$ & - & - \\
\hline & MET & $9.1 / 0.9$ & - & - \\
\hline \multirow{6}{*}{$\begin{array}{c}d \theta_{\mathrm{v}} / d h^{\mathrm{c}} \\
\left(\mathrm{K} \mathrm{km}^{-1}\right)\end{array}$} & $\mathrm{RB}$ & 39.7 & 20.0 & - \\
\hline & AERO & 29.6 & 17.9 & - \\
\hline & MET & 23.0 & 23.9 & - \\
\hline & BAe-146 & 30.4 & - & - \\
\hline & AERO & 24.7 & - & - \\
\hline & MET & 21.8 & - & - \\
\hline \multirow{6}{*}{$\begin{array}{l}d q_{\mathrm{v}} / d h^{\mathrm{c}} \\
\left(\mathrm{g} \mathrm{kg}^{-1} \mathrm{~km}^{-1}\right)\end{array}$} & $\mathrm{RB}$ & -16.8 & -12.9 & - \\
\hline & AERO & -11.6 & -12.1 & - \\
\hline & MET & -8.2 & -12.5 & - \\
\hline & BAe-146 & -11.2 & - & - \\
\hline & AERO & -6.0 & - & - \\
\hline & MET & -5.1 & - & - \\
\hline \multirow{6}{*}{ MBLH (m) } & $\mathrm{RB}$ & $1263 / 113$ & $1431 / 163$ & $1313 / 151$ \\
\hline & AERO & $1136 / 153$ & $1398 / 186$ & $1213 / 202$ \\
\hline & MET & $1197 / 189$ & $1686 / 139$ & $1343 / 285$ \\
\hline & BAe-146 & $1122 / 130$ & - & - \\
\hline & AERO & $1051 / 168$ & - & - \\
\hline & MET & $1133 / 184$ & - & - \\
\hline \multicolumn{5}{|l|}{ Winds, SST } \\
\hline \multirow{3}{*}{$U_{10}\left(\mathrm{~m} \mathrm{~s}^{-1}\right)^{\mathrm{f}}$} & $\mathrm{RB}$ & $4.8 / 1.3$ & $8.2 / 1.3$ & $6.2 / 2.1$ \\
\hline & AERO & $4.9 / 1.6$ & $8.8 / 1.1$ & $6.4 / 2.4$ \\
\hline & MET & $4.8 / 1.4$ & $8.8 / 1.2$ & $6.4 / 2.3$ \\
\hline \multirow{3}{*}{ SST (K) } & $\mathrm{RB}$ & $291.2 / 0.9$ & $291.7 / 0.6$ & $291.4 / 0.8$ \\
\hline & AERO & $290.9 / 0.5$ & $291.7 / 0.5$ & 291.3/0.6 \\
\hline & MET & $290.9 / 0.5$ & $291.7 / 0.5$ & 291.3/0.6 \\
\hline \multicolumn{5}{|c|}{ Accumulation mode aerosol $(0.156-2.69 \mu \mathrm{m})$ concentration } \\
\hline \multirow{2}{*}{$N_{\mathrm{a}}\left(\mathrm{cm}^{-3}\right)$} & $\mathrm{C}-130$ & $243 / 147$ & $105 / 95$ & $184 / 144$ \\
\hline & AERO & $160 / 68$ & $81 / 36$ & $126 / 68$ \\
\hline \multicolumn{5}{|c|}{ Droplet number concentration } \\
\hline \multirow{2}{*}{$N_{\mathrm{d}}\left(\mathrm{cm}^{-3}\right)$} & C-130 & $203 / 84$ & $85 / 55$ & $154 / 93$ \\
\hline & AERO & $160 / 94$ & $75 / 56$ & $124 / 90$ \\
\hline \multicolumn{5}{|c|}{ DMS transfer velocity $\left(K_{\mathrm{w}}\right)$, MBL DMS and $\mathrm{SO}^{2}$ air concentrations } \\
\hline \multirow{2}{*}{$K_{\mathrm{W}}\left(\mathrm{cm} \mathrm{h}^{-1}\right)$} & $\mathrm{RB}$ & $3.80 / 1.96$ & $9.04 / 2.95$ & $5.69 / 3.44$ \\
\hline & AERO & $6.29 / 3.53$ & $15.85 / 3.76$ & $9.73 / 5.85$ \\
\hline \multirow{2}{*}{ DMS Air (pptv) } & $\mathrm{RB}$ & $43.2 / 27.5$ & $78.2 / 21.6$ & $56.9 / 30.6$ \\
\hline & AERO & $138.4 / 49.6$ & $216.5 / 41.0$ & $169.1 / 60.1$ \\
\hline \multirow{2}{*}{$\mathrm{SO}_{2}$ air (pptv) } & C-130 & $54.0 / 74.5$ & $27.8 / 18.7$ & $40.8 / 55.7$ \\
\hline & AERO & $38.8 / 71.6$ & $11.8 / 17.3$ & $25.2 / 53.6$ \\
\hline
\end{tabular}

${ }^{a}$ Coastal and remote regions are defined as east and west of $78^{\circ} \mathrm{W}$ within the model domain, respectively. ${ }^{\mathrm{b}}$ For the lowest $1 \mathrm{~km}$ within MBL. ${ }^{\mathrm{c}}$ For the inversion layer. ${ }^{\mathrm{d}}$ Including 23 and 54 (RB) radiosonde profiles over the remote and coastal regions, respectively. ${ }^{e}$ Including 31 (BAe-146) dropsonde profiles over the coastal region. ${ }^{\mathrm{f}}$ the value for the RB is derived using measurements on the ship and the COARE 3.0 bulk flux model (Fairall et al., 2011). 
from both simulations, on average, are biased high within MBL (biases of $0.4-1.1 \mathrm{~g} \mathrm{~kg}^{-1}$ ) and in lower free troposphere (above MBL and $<2 \mathrm{~km}$, biases of $1.6-2.2 \mathrm{~g} \mathrm{~kg}^{-1}$ ) with more significant biases seen in the comparisons with the dropsondes. The larger biases in AERO and MET compared to the dropsondes are associated with the larger biases in model predictions during 2-10 November, when the observed temperature inversion is weaker and the vertical variability in humidity is large (with the possible presence of multi-cloud layers). Toniazzo et al. (2011) also noted early November to be a period with reduced synoptic-scale variability, lower inversion heights and increased cloud cover. The RB had measurements on 2-3 November before a 6-day break in sampling and the mean profiles were less affected by profiles measured during this synoptic episode. Over the remote region, the simulated mean temperature and humidity are in excellent agreement with AERO simulations with the simulated mean values being not statistically different (at $98 \%$ confidence level) from observations at most vertical layers from the surface to $2 \mathrm{~km}$. Over this region, the biases of the simulated mean profile in MET are mostly within the inversion layer.

As shown in Table 3 and Fig. 1, the AERO simulation better predicts the temperature and humidity gradients within the inversion layer than the MET over both regions, except for the humidity gradient over the remote region.

The zonal and diurnal variations of predicted MBL depths are compared to those from the RB and BAe-146 observations, as shown in Fig. 2 and Table 3. Since BAe-146 dropsonde data were released within a narrow time window during the day (14:00-16:00 UTC), they have not been included in the diurnal variability plot (bottom panel of Fig. 2). In simulations using the YSU PBL scheme, clouds often form on top of the on-line diagnosed PBL heights. Therefore, the MBL depth is determined as the lowest height where the local temperature gradient is at least 3 times the gradient below it. When a reasonable MBL depth is not found using this approach, the MBL depths for both model simulations and observations are determined from humidity profiles in a similar manner. The clear longitude dependence of observed MBL depths (in the range of 900-1600 m), which deepen farther away from the coast, is also reflected in both AERO and MET simulations (Fig. 2). The MBL depth from the MET simulation has a positive bias of $\sim 250 \mathrm{~m}$ (Table 3 ) over the remote region. Inclusion of interactive aerosols in the AERO simulation leads to a lower MBL than in MET, giving better agreement with observations over the remote region (Table 3). However, the mean MBL depth from AERO is approximately $\sim 100 \mathrm{~m}$ too low over the coastal region compared to radiosondes and dropsondes. The lower simulated MBL depths when aerosols are included are linked to the reduction of MBL top entrainment and mean subsidence rates which are discussed later in more detail. The WRF simulations described by Rahn and Garreaud (2010) using the Mellor-Yamada-Janjic PBL scheme had lower MBL depths
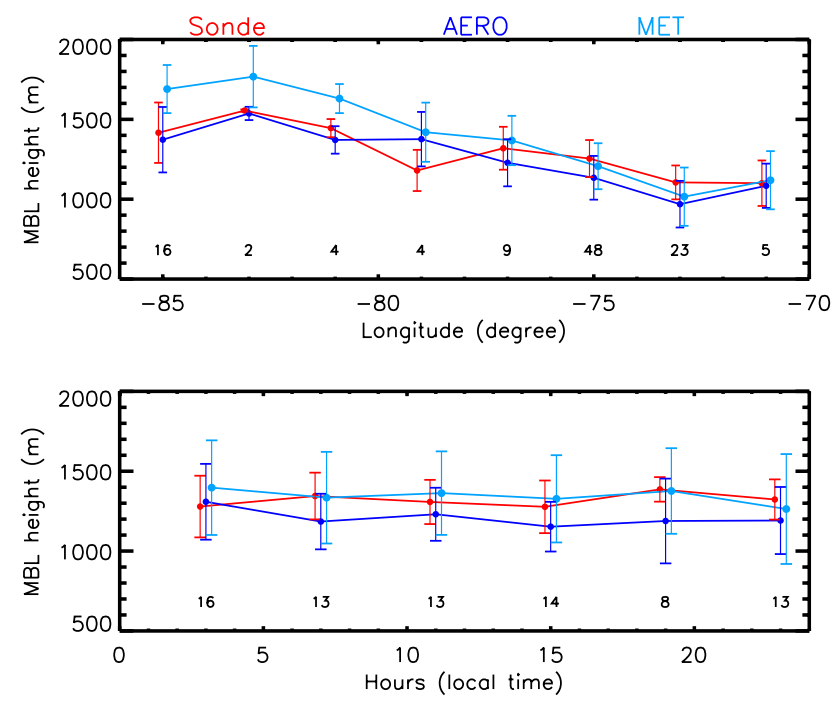

Fig. 2. Longitudinal and diurnal variations of the MBL heights derived from the RB radiosonde and BAe-146 dropsonde measurements (red), and from the AERO (blue) and MET (light blue) simulations. Only radiosonde profiles are included in the bottom panel. The MBL heights are determined from temperature profiles in combination with humidity profiles. The numbers of observational data used are indicated below the data points.

than observations, which is consistent with our results near the coastal region but not over the remote region. This might be due to differences in model setup, including the use of a different PBL scheme. As with Rahn and Garreaud (2010), the low bias in the mean MBL depth near the coast in both AERO and MET simulations could be explained by an overprediction of low-level onshore wind speeds which lead to high biases in low-level divergence over a several hundred meter vertical layer resulting in lowering of MBL heights.

No significant diurnal variations in MBL depth are observed or modeled (bottom panel of Fig. 2). The lack of distinct diurnal variations in MBL depth is consistent with Zuidema et al. (2009) and Rahn and Garreaud (2010) that describe weak dependence of MBL depth on air-sea temperature differences. In addition, there is considerable day-to-day and spatial variability in MBL heights as reflected in standard deviations ( $\sigma=151 \mathrm{~m}$ for the radiosonde observations; $\sigma=202 \mathrm{~m}$ and $285 \mathrm{~m}$ for the AERO and MET, respectively).

\subsection{Aerosol and cloud droplets}

\subsubsection{Aerosol and cloud droplet number concentrations}

MBL processes, transport, and anthropogenic and natural aerosol and precursor emissions influence the distribution of aerosol. In this section, we first compare the model simulated and aircraft in-situ measured accumulation mode aerosol number $\left(N_{\mathrm{a}}, 0.156-2.69 \mu \mathrm{m}\right.$, Fig. 3 and Table 3$)$ and cloud droplet number concentrations $\left(N_{\mathrm{d}}\right.$, Fig. 3 and Table 3 ). 

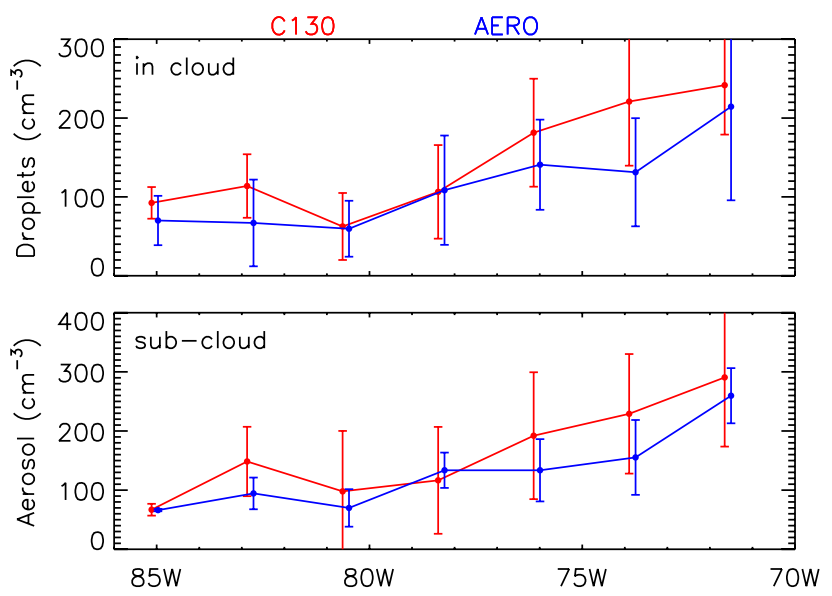

Fig. 3. Droplet number concentrations in the cloud layer and aerosol number concentrations in the sub-cloud layer observed on the C-130 aircraft (red) and predicted by the AERO simulation (blue). The aerosol size range is $0.156-2.69 \mu \mathrm{m}$ in diameter for observations and $0.156-2.5 \mu \mathrm{m}$ for the model. The error bar represents $\pm 1 \sigma$.

Observed aerosol and cloud droplet number concentrations both have strong longitudinal gradients over the coastal region. As shown in the bottom panel of Fig. 3, the observed $N_{\mathrm{a}}$ in the sub-cloud layer (on average $170 \mathrm{~m}$ above sea surface) is $290 \pm 117 \mathrm{~cm}^{-3}$ just west of the coast $\left(71-72^{\circ} \mathrm{W}\right)$, decreasing to $117 \pm 93 \mathrm{~cm}^{-3}$ at $\sim 78^{\circ} \mathrm{W}$. The mean observed concentration over the remote region is $105 \pm 95 \mathrm{~cm}^{-3}$ (Table 3). The modeled $N_{\mathrm{a}}$ in the sub-cloud layer resembles the observed in longitudinal variation. However, simulated $N_{\text {a }}$ concentrations (from model size bins 3-6) are lower than observations with mean biases of $34 \%$ and $23 \%$ over the coastal and remote regions, respectively. The predicted size distribution peaks at model size bin $2(0.08-0.16 \mu \mathrm{m}$ in diameter), and the number concentration in model size bin 2 is about 1.5 times the modeled $N_{\mathrm{a}}$ concentration (includes model bins 3-6). Thus, errors in the size distribution could contribute to the number bias. Given the multitude of source and sink processes that affect aerosol number concentrations, the $\sim 30 \% N_{\mathrm{a}}$ bias is quite good.

Overall, simulated and observed cloud droplet number concentrations exhibit the same longitudinal gradient as that of the aerosol. This is expected, since hygroscopic aerosol particles acting as $\mathrm{CCN}$ can activate and form new cloud droplets. The observed $N_{\mathrm{d}}$ has a mean value of $240 \mathrm{~cm}^{-3}$ near the coast and decreases to below $120 \mathrm{~cm}^{-3}$ at $\sim 78^{\circ} \mathrm{W}$, and further decreases to a mean value of $85 \pm 55 \mathrm{~cm}^{-3}$ over the remote region. The observed longitudinal variation in $N_{\mathrm{d}}$ is in general agreement with the variation shown in Fig. 11 of Allen et al. (2011) in which CDP measurements on both the BAe-146 and C-130 were included. The domain average near-surface $N_{\mathrm{d}}$ of $154 \mathrm{~cm}^{-3}$ measured by the $\mathrm{C} 130$ (Table 3) is in-between the mean $N_{\mathrm{d}}$ values of $164 \mathrm{~cm}^{-3}$ and $142 \mathrm{~cm}^{-3}$ based on aircraft and MODIS measurements during the VOCALS-REx obtained by Bretherton et al. (2010b), in which their focus region was along $20^{\circ} \mathrm{S}$ and multiple aircraft measurements of $N_{\mathrm{d}}$ were included. The modeled cloud droplet concentrations are lower by $21 \%$ and $13 \%$ over the coastal and the remote regions, respectively, which is related to the low biases in the predicted aerosol concentrations.

Aerosol, CCN and cloud droplet number concentrations over the SEP are strongly influenced by pollution outflow from the continent. In Fig. 10 of Bretherton et al. (2010b), daily MODIS-derived $N_{\mathrm{d}}$ were compared against aircraft measurements, and it showed the occurrence of a few strong outflow events along $20^{\circ} \mathrm{S}$ over the SEP. The longitudetime plot of model (AERO) predicted $\mathrm{CCN}$ concentrations (at $0.1 \%$ supersaturation) at $975 \mathrm{hPa}$ are shown in Fig. 4 (left panel). The model succeeds in capturing the timing and strength of the observed outflow events shown in Fig. 10 of Bretherton et al. (2010b). During the VOCALS-REx, the strongest pollution outflow event along $20^{\circ} \mathrm{S}$ peaked on 18 October, and the cleanest period was around 8 November. The four contour plots on the right panel of Fig. 4 illustrate the horizontal distribution of MODIS-derived (using Eq. (2) of George and Wood, 2010) and model-predicted $N_{\mathrm{d}}$ during the two time periods, respectively. Model simulated $N_{\mathrm{d}}$ compares reasonably well with observations. The model reproduces the outflow pattern from coastline towards the ocean with a band of high $N_{\mathrm{d}}$ several-degrees wide in longitude along the coast. Considering the relatively large uncertainties in satellite-derived $N_{\mathrm{d}}$ due to averaging over only several instantaneous satellite snapshots and the timing differences between satellite overpasses and model outputs, the agreement in the outflow patterns is remarkably good. The model also captures $N_{\mathrm{d}}$ spatial patterns during the clean event. The accurate predictions of both events demonstrate the model's ability to capture daily/synoptic scale variations of aerosol and clouds, and suggest that the model is suitable for studies at such scales (e.g., pollution outflow studies), which is another advantage of using WRF-Chem with the prognostic treatment of aerosols and cloud-aerosol interactions.

\subsubsection{Aerosol mass and composition}

Aerosol mass and composition are other important measures that can be used to derive additional aerosol properties, such as aerosol volume, surface area, and density, when combined with aerosol number. Over the SEP, th observed and simulated submicron aerosol mass is dominated by sulfate over both the coastal and remote regions for the measured chemical species (i.e., sulfate, nitrate, ammonium, organic carbon, chloride, and sodium). Observed and modeled MBL submicron aerosol mass concentrations of the different chemical species are shown in Fig. 5 and Table 4. Observations on different platforms and the AERO both show that sulfate contributes to $>55 \%$ of the total submicron aerosol mass measured by the AMS. 

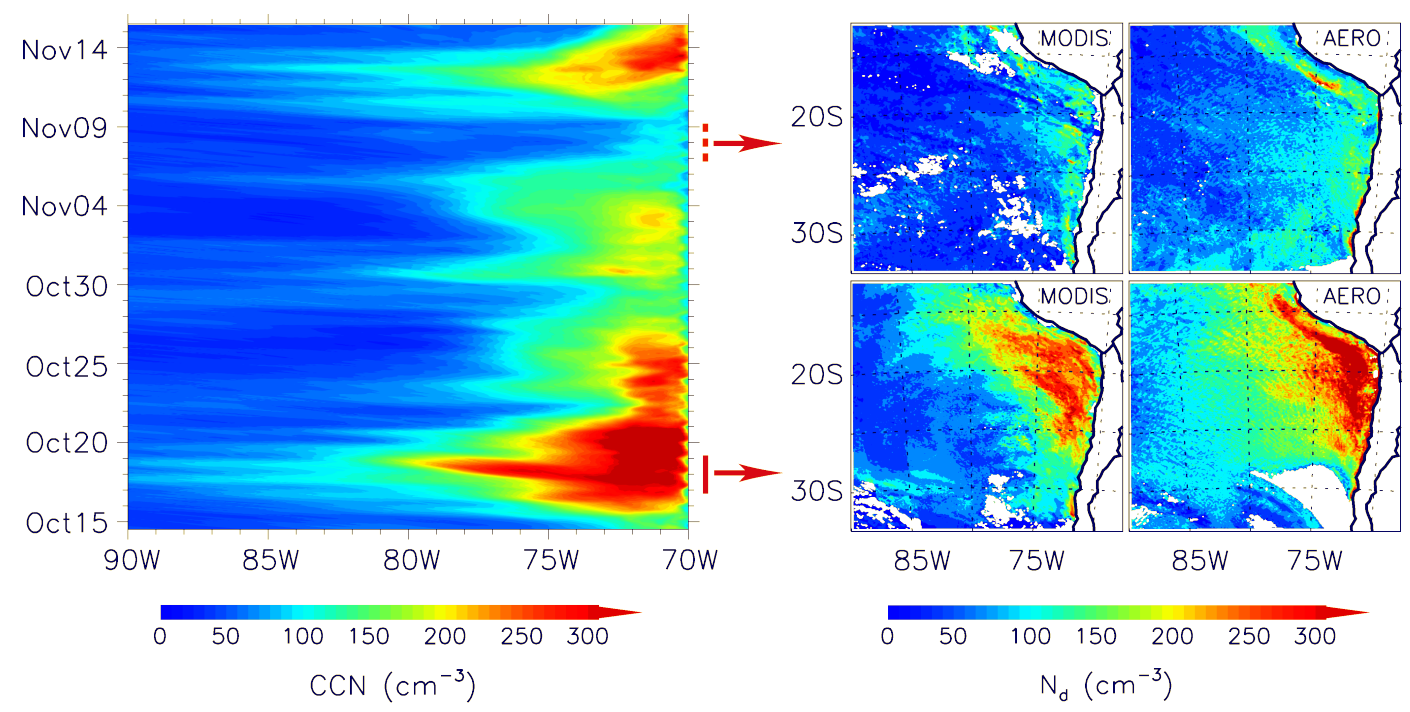

Fig. 4. Longitude-time plot of model (AERO) predicted $\mathrm{CCN}$ (at $0.1 \%$ supersaturation) concentrations at $975 \mathrm{hPa}$ along $20^{\circ} \mathrm{S}\left( \pm 2.5^{\circ}\right.$ in latitude), and illustration of episodic horizontal distribution of MODIS-derived (Aqua) cloud droplet number concentration ( $\mathrm{N}_{d}$ ) and AEROpredicted cloud top $N_{\mathrm{d}}$ during a strong outflow event (peaks on 18 October 2011, red solid line) and during a clean period (around 8 November 2011, red dash line). To obtain a more complete data coverage over the domain, MODIS $N_{\mathrm{d}}$ was composed from available retrievals in 3 days (centered at the peak of the event), and correspondingly only model predictions at around satellite overpass time (18:00-20:00 UTC) during the 3-day period are included.

The predicted non-sea-salt submicron sulfate concentrations over the coastal region are roughly $37 \%$ and $15 \%$ lower than the observed values, which are $0.85 \mu \mathrm{g} \mathrm{m}^{-3}$ and $1.13 \mu \mathrm{g} \mathrm{m}^{-3}$ based on the AMS instruments onboard the $\mathrm{C}-130$ and RB, respectively. The AMS and PILS on the G-1 measured sulfate concentrations of $1.10 \mu \mathrm{g} \mathrm{m}^{-3}$ and $1.29 \mu \mathrm{g} \mathrm{m}^{-3}$, respectively. Over the coastal region, the high mean sulfate concentration $\left(1.81 \mu \mathrm{g} \mathrm{m}^{-3}\right.$, Table 4$)$ measured by the AMS on the BAe-146 is dominated by the high values (mean of $2.82 \mu \mathrm{g} \mathrm{m}^{-3}$ ) in a pollution plume study flight on 10 November 2008. Excluding this flight, the mean sulfate concentration $\left(1.13 \mu \mathrm{g} \mathrm{m}^{-3}\right)$ over the coastal region observed on the BAe-146 is in close agreement with those measured on the RB and C-130 (Table 4), which is underpredicted by $30 \%$ in AERO. Observed submicron sulfate concentrations from different platforms are $0.27-0.39 \mu \mathrm{g} \mathrm{m}^{-3}$ (Table 4) over the remote region. These observed values over both coastal and remote regions are in general agreement with those in Fig. 8 of Allen et al. (2011). Over the coastal region, the higher mean sulfate concentration from the RB in Table 4 compared to Fig. 8 of Allen et al. (2011) is mostly because we only used the RB observations within the VOCALS-REx period (15 October-15 November), which is a subset of the RB observations. For the supermicron sulfate, observations from the CIS on the RB show similar values $\left(\sim 0.55 \mu \mathrm{g} \mathrm{m}^{-3}\right)$ between remote and coastal regions. The simulated supermicron sulfate was in good agreement $(\sim 20 \%$ lower $)$ with those observed on the RB over the coastal region, but was $80 \%$ lower over the remote region. The larger bias over the remote region suggests the underestimation of sulfate from DMS oxidation or too rapid sulfate removal, as addressed in more detail later in Sect. 4.

For ammonium mass concentrations, the simulated values are significantly smaller than the corresponding measurements for both the submicron $\left(0.07-0.09 \mu \mathrm{g} \mathrm{m}^{-3}\right.$ vs. $0.11-$ $0.37 \mu \mathrm{g} \mathrm{m}^{-3}$ ) measured on different platforms and supermicron sizes $\left(0.08 \mu \mathrm{g} \mathrm{m}^{-3}\right.$ vs. $\left.0.23 \mu \mathrm{g} \mathrm{m}^{-3}\right)$ measured on the $\mathrm{RB}$ over the coastal region (Table 4). Over the remote region, the detected ammonium concentrations (Table 4) are only slightly above instrument detection limits. The differences between values observed on the RB and those of the $\mathrm{C}-130$ over this region may reflect the difference in instrument detection limits. The corresponding predicted submicron ammonium is also small $\left(<0.03 \mu \mathrm{g} \mathrm{m}^{-3}\right)$ over the remote region.

Regarding nitrate aerosol, the PILS on the G-1 detected $0.12 \pm 0.10 \mu \mathrm{g} \mathrm{m}^{-3}$ (boundary layer, mission-averaged). In contrast, nitrate was not detected by the AMS. This difference is consistent with the explanation that uptake of nitric acid advected to the MBL occurred only on sea-salt aerosol, but not on acidic sulfate aerosol. Upon acidification by nitric acid, sea-salt aerosol loses hydrochloric acid by volatilization, leaving behind sodium nitrate, which was undetectable by the AMS because of its refractory nature. The loss of chloride in sea-salt aerosol results in a lowered chloride to sodium ratio than that of the seawater, referred to as chloride deficit. The chloride deficit observed on G-1 was 0.77 (molar ratio, MBL, mission-averaged) reduced from 1.16 of 
Table 4. Observed and simulated MBL submicron and supermicron aerosol composition.

\begin{tabular}{|c|c|c|c|c|c|}
\hline Aerosol & $\begin{array}{l}\text { Platform (instrument)/ } \\
\text { Simulations }\end{array}$ & $\begin{array}{l}\text { Diameter } \\
(\mu \mathrm{m})\end{array}$ & $\begin{array}{l}\text { Coastal region } \\
\text { Mean/std } \\
\left(\mu \mathrm{g} \mathrm{m}^{-3}\right)\end{array}$ & $\begin{array}{l}\text { Remote region } \\
\text { Mean/std } \\
\left(\mu \mathrm{g} \mathrm{m}^{-3}\right)\end{array}$ & $\begin{array}{l}\text { Both regions } \\
\text { Mean/std } \\
\left(\mu \mathrm{g} \mathrm{m}^{-3}\right)\end{array}$ \\
\hline \multirow{7}{*}{ Sulfate } & $\begin{array}{l}\text { C-130 (AMS) } \\
\text { AERO }\end{array}$ & $0.05-0.5$ & $\begin{array}{l}0.85 / 1.12 \\
0.72 / 0.72\end{array}$ & $\begin{array}{l}0.27 / 0.33 \\
0.16 / 0.11\end{array}$ & $\begin{array}{l}0.63 / 0.95 \\
0.50 / 0.63\end{array}$ \\
\hline & $\begin{array}{l}\text { RB (AMS) } \\
\text { AERO }\end{array}$ & $0.06-1.0$ & $\begin{array}{l}1.13 / 0.85 \\
0.71 / 0.40\end{array}$ & $\begin{array}{l}0.39 / 0.26 \\
0.15 / 0.08\end{array}$ & $\begin{array}{l}0.87 / 0.79 \\
0.51 / 0.4\end{array}$ \\
\hline & $\begin{array}{l}\text { BAe-146 (AMS) } \\
\text { AERO }\end{array}$ & $0.05-0.5$ & $\begin{array}{l}1.81 / 1.92 \\
0.98 / 0.73\end{array}$ & $\begin{array}{l}0.27 / 0.19^{b} \\
0.22 / 0.11\end{array}$ & $\begin{array}{l}1.59 / 1.86^{\mathrm{b}} \\
0.87 / 0.73\end{array}$ \\
\hline & $\begin{array}{l}\text { G-1 (AMS) } \\
\text { AERO }\end{array}$ & $0.06-0.6$ & $\begin{array}{l}1.10 / 0.92 \\
1.42 / 0.96\end{array}$ & $\begin{array}{l}- \\
-\end{array}$ & $\begin{array}{l}- \\
-\end{array}$ \\
\hline & $\begin{array}{l}\text { G-1 (PILS) } \\
\text { AERO }\end{array}$ & $0.06-1.5$ & $\begin{array}{l}1.29 / 1.01 \\
1.63 / 1.02\end{array}$ & - & - \\
\hline & $\begin{array}{l}\text { RB (CIS) } \\
\text { AERO }\end{array}$ & $<1.1$ & $\begin{array}{l}1.08 / 0.95 \\
0.76 / 0.36\end{array}$ & $\begin{array}{l}0.31 / 0.15 \\
0.20 / 0.15\end{array}$ & $0.76 / 0.82$ \\
\hline & $\begin{array}{l}\text { RB (CIS) } \\
\text { AERO }\end{array}$ & $1.1-10$ & $\begin{array}{l}0.53 / 0.14 \\
0.41 / 0.17\end{array}$ & $\begin{array}{l}0.59 / 0.16 \\
0.12 / 0.07\end{array}$ & $\begin{array}{l}0.55 / 0.15 \\
0.29 / 0.20\end{array}$ \\
\hline \multirow{5}{*}{ Ammonium } & $\begin{array}{l}\text { C-130 (AMS) } \\
\text { AERO }\end{array}$ & $0.05-0.5$ & $\begin{array}{l}0.13 / 0.24 \\
0.07 / 0.07\end{array}$ & $\begin{array}{l}0.03 / 0.08 \\
0.01 / 0.02 \\
\end{array}$ & $\begin{array}{l}0.09 / 0.20 \\
0.05 / 0.06\end{array}$ \\
\hline & $\begin{array}{l}\text { RB(AMS) } \\
\text { AERO }\end{array}$ & $0.06-1.0$ & $\begin{array}{l}0.30 / 0.12 \\
0.09 / 0.05\end{array}$ & $\begin{array}{l}0.20 / 0.04 \\
0.01 / 0.01\end{array}$ & $\begin{array}{l}0.28 / 0.11 \\
0.08 / 0.06\end{array}$ \\
\hline & $\begin{array}{l}\text { BAe-146 (AMS) } \\
\text { AERO }\end{array}$ & $0.05-0.5$ & $\begin{array}{l}0.37 / 0.29 \\
0.07 / 0.05\end{array}$ & $\begin{array}{l}0.04 / 0.13^{\mathrm{b}} \\
0.02 / 0.02\end{array}$ & $\begin{array}{l}0.32 / 0.29^{b} \\
0.06 / 0.05\end{array}$ \\
\hline & $\begin{array}{l}\text { G-1 (AMS) } \\
\text { AERO }\end{array}$ & $0.06-0.6$ & $\begin{array}{l}0.11 / 0.09 \\
0.09 / 0.05\end{array}$ & $\begin{array}{l}- \\
-\end{array}$ & $\begin{array}{l}- \\
-\end{array}$ \\
\hline & $\begin{array}{l}\text { RB (CIS) } \\
\text { AERO }\end{array}$ & $<1.1$ & $\begin{array}{l}0.23 / 0.17 \\
0.08 / 0.06\end{array}$ & $\begin{array}{l}0.07 / 0.04 \\
0.01 / 0.02\end{array}$ & $\begin{array}{l}0.16 / 0.15 \\
0.05 / 0.06\end{array}$ \\
\hline \multirow{4}{*}{ Organics } & $\begin{array}{l}\text { C-130 (AMS) } \\
\text { AERO }\end{array}$ & $0.05-0.5$ & $\begin{array}{l}0.19 / 0.47 \\
0.13 / 0.10 \\
\end{array}$ & $\begin{array}{l}0.08 / 0.14 \\
0.04 / 0.03 \\
\end{array}$ & $\begin{array}{l}0.14 / 0.39 \\
0.10 / 0.10 \\
\end{array}$ \\
\hline & $\begin{array}{l}\text { RB (AMS) } \\
\text { AERO }\end{array}$ & $0.06-1.0$ & $\begin{array}{l}0.32 / 0.13 \\
0.14 / 0.07\end{array}$ & $\begin{array}{l}0.25 / 0.07 \\
0.03 / 0.02\end{array}$ & $\begin{array}{l}0.29 / 0.12 \\
0.11 / 0.08\end{array}$ \\
\hline & $\begin{array}{l}\text { BAe-146 (AMS) } \\
\text { AERO }\end{array}$ & $0.05-0.5$ & $\begin{array}{l}0.21 / 0.32 \\
0.12 / 0.06\end{array}$ & $\begin{array}{l}0.04 / 0.72^{b} \\
0.05 / 0.03\end{array}$ & $\begin{array}{l}0.19 / 0.41^{b} \\
0.11 / 0.06\end{array}$ \\
\hline & $\begin{array}{l}\text { G-1 (AMS) } \\
\text { AERO }\end{array}$ & $0.06-0.6$ & $\begin{array}{l}0.16 / 0.06 \\
0.17 / 0.19\end{array}$ & - & - \\
\hline \multirow{3}{*}{ Chloride } & $\begin{array}{l}\text { G-1 (PILS) } \\
\text { AERO }\end{array}$ & $0.06-1.5$ & $\begin{array}{l}0.25 / 0.39 \\
0.32 / 0.23 \\
\end{array}$ & - & - \\
\hline & $\begin{array}{l}\text { RB (CIS) } \\
\text { AERO }\end{array}$ & $<1.1$ & $\begin{array}{l}0.03 / 0.02 \\
0.02 / 0.03\end{array}$ & $\begin{array}{l}0.06 / 0.02 \\
0.11 / 0.05\end{array}$ & $\begin{array}{l}0.04 / 0.02 \\
0.06 / 0.06\end{array}$ \\
\hline & $\begin{array}{l}\text { RB (CIS) } \\
\text { AERO }\end{array}$ & $1.1-10$ & $\begin{array}{l}3.02 / 1.14 \\
6.25 / 2.23\end{array}$ & $\begin{array}{l}4.18 / 1.27 \\
8.81 / 2.70\end{array}$ & $\begin{array}{l}3.41 / 1.34 \\
7.19 / 2.72\end{array}$ \\
\hline \multirow{3}{*}{ Sodium } & $\begin{array}{l}\text { G-1 (PILS) } \\
\text { AERO }\end{array}$ & $0.06-1.5$ & $\begin{array}{l}0.28 / 0.36 \\
0.35 / 0.16\end{array}$ & - & - \\
\hline & $\begin{array}{l}\text { RB (CIS) } \\
\text { AERO }\end{array}$ & $<1.1$ & $\begin{array}{l}0.07 / 0.02 \\
0.14 / 0.04\end{array}$ & $\begin{array}{l}0.06 / 0.02 \\
0.14 / 0.04\end{array}$ & $\begin{array}{l}0.07 / 0.02 \\
0.14 / 0.04\end{array}$ \\
\hline & $\begin{array}{l}\text { RB (CIS) } \\
\text { AERO }\end{array}$ & $1.1-10$ & $\begin{array}{l}1.80 / 0.57 \\
4.23 / 1.42\end{array}$ & $\begin{array}{l}2.35 / 0.69 \\
5.78 / 1.77\end{array}$ & $\begin{array}{l}2.02 / 0.66 \\
4.87 / 1.71\end{array}$ \\
\hline
\end{tabular}

${ }^{\text {a }}$ Coastal and remote regions are defined as east and west of $78^{\circ} \mathrm{W}$ within the model domain, respectively.

$\mathrm{b}$ The BAe-146 measurement data only covered the east edge of the remote region $\left(78-81^{\circ} \mathrm{W}\right.$ with mean longitude of $\left.79^{\circ} \mathrm{W}\right)$. 


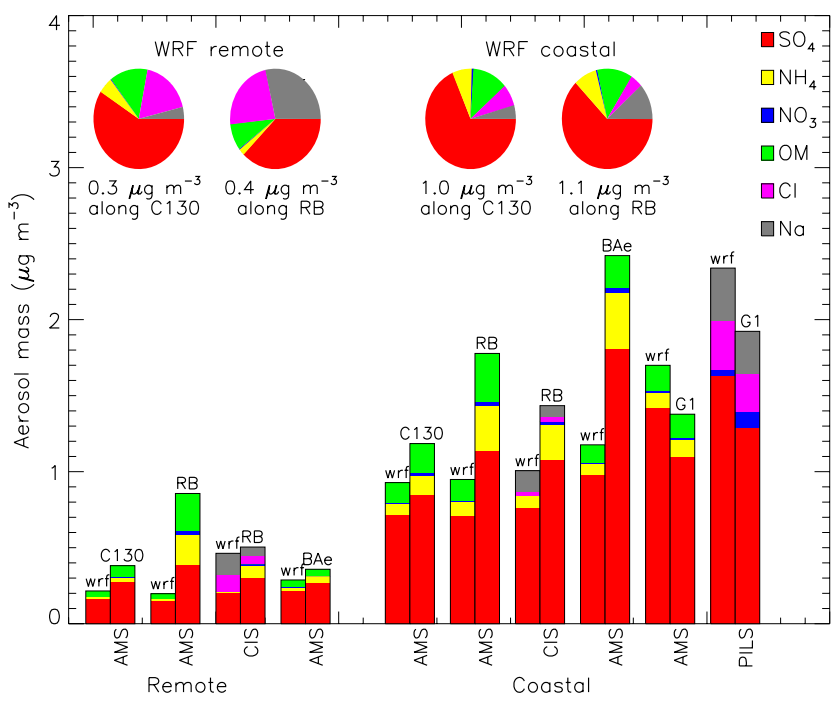

Fig. 5. MBL submicron aerosol mass composition from VOCALSREx measurements and from the AERO simulation. The measurements are provided by AMS instruments onboard the C-130, RB, and G-1 and those sampled by the CIS and a PILS onboard the RB and G-1, respectively. The pie charts and the total aerosol mass provided below them are based on the AERO simulation; only data along $\mathrm{C}-130$ and $\mathrm{RB}$ tracks at the sampling time are included into the calculations. The dividing longitude for the coastal and remote regions is $78^{\circ} \mathrm{W}$, and the $\mathrm{BAe}-146$ measurement data only covered the east edge of the remote region $\left(78-81^{\circ} \mathrm{W}\right.$ with a mean longitude of $\left.79^{\circ} \mathrm{W}\right)$.

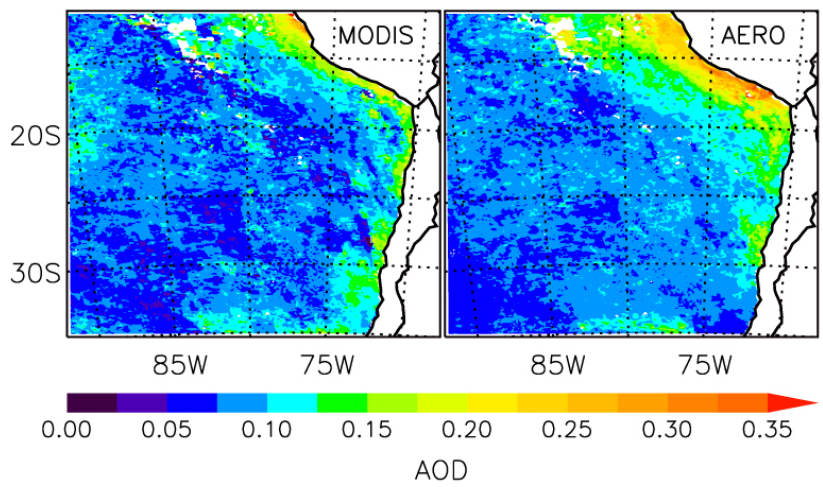

Fig. 6. AOD from MODIS (Aqua) measurements (left panel) and from the AERO simulation (right panel) during the VOCALS-REx period. Only model data at satellite scanning locations and times are included.

seawater. Chloride deficit was also observed on the RB during VOCALS-REx (Yang et al., 2011). We note that chloride deficit is well simulated by the AERO, but nitrate was underpredicted by $\sim 50 \%$ compared to the PILS.

The observed organic matter $(\mathrm{OM})$ concentrations over the coastal region are $0.16-0.21 \mu \mathrm{g} \mathrm{m}^{-3}$ for smaller size $(<0.6 \mu \mathrm{m})$ particles measured on the flight platforms and $0.32 \mu \mathrm{g} \mathrm{m}^{-3}$ for the submicron particles measured on the RB.
The simulated values, on average, agree with that of G-1 within $6 \%$, while they are underpredicted in the model by 25-56\% compared to those on other platforms. Over the remote region, the $\mathrm{C}-130$ and $\mathrm{RB}$ observed very different OM concentrations $\left(0.08 \mu \mathrm{g} \mathrm{m}^{-3}\right.$ vs. $\left.0.25 \mu \mathrm{g} \mathrm{m}^{-3}\right)$, which are likely related to differences in sampling upper cutoff diameters and instrument detection limits. AERO does not include oceanic emissions of organic compounds, so the simulated $\sim 0.03-0.04 \mu \mathrm{g} \mathrm{m}^{-3} \mathrm{OM}$ over the remote region is solely due to continental sources. According to Hawkins et al. (2010), OM over the SEP has a dominant contribution from anthropogenic sources, and an additional, smaller contribution from primary marine sources based on measured functional groups and trace elements during VOCALS-REx. Lower OM concentrations in MOSAIC could also result from the omission of secondary organic aerosol (SOA) formation processes. The contribution of SOA to OM is variable depending on factors such as precursor concentrations, oxidant level, etc, and the organic mass associated with clean marine air (Hawkins et al., 2010).

The mean simulated chloride and sodium aerosol mass with diameter below $1.5 \mu \mathrm{m}$ is in good agreement $(\sim 25 \%$ higher) with those sampled by the PILS $\left(0.25 \mu \mathrm{g} \mathrm{m}^{-3}\right.$ for chloride and $0.28 \mathrm{\mu g} \mathrm{m}^{-3}$ for sodium) over the coastal region. The submicron chloride sampled on the RB has a domainaverage of $0.04 \mu \mathrm{g} \mathrm{m}^{-3}$, which is overpredicted by $\sim 50 \%$ in AERO (Table 4). The predicted supermicron chloride concentrations $\left(6.25-8.81 \mathrm{~g} \mathrm{~m}^{-3}\right)$ are approximately twice the observed values $\left(3.02-4.18 \mu \mathrm{g} \mathrm{m}^{-3}\right)$ on the $\mathrm{RB}$ over the coastal and the remote regions (Table 4). The AERO predicted sodium concentrations are also a factor of 2.0-2.4 higher than the RB observed values (Table 4). Note that the composition of freshly-emitted sea-salt particles reflects that of seawater, treating sea salt as $\mathrm{NaCl}$ in the model implies an overestimation of the sodium and chloride emissions by $25 \%$ and $10 \%$, respectively. After accounting for this effect, the supermicron sodium and chloride are overestimated by a factor of 1.9. The overestimation in the supermicron sizes could be related to errors in the predicted sea-salt size spectrum, which could also affect modeled dry deposition of larger particles.

As shown in Fig. 5, both observations and the simulation show 2-3 times higher total submicron mass concentration over the coastal region compared to the remote region. This highlights the importance of continental sources and the resulting outflow over maritime regions near the coast.

\subsubsection{AOD}

AOD is an important wavelength-dependent property that directly relates to aerosol direct radiative forcing, and is a function of the aerosol loading, composition, and size distribution. The AOD at $0.55 \mu \mathrm{m}$ spectral wavelength from MODIS is compared with the coincident data from AERO in Fig. 6 for the VOCALS-REx period. The model reproduces the 
Table 5. Observed and simulated cloud properties.

\begin{tabular}{|c|c|c|c|c|}
\hline $\begin{array}{l}\text { Variable } \\
\text { (Units) }\end{array}$ & $\begin{array}{l}\text { Platform/ } \\
\text { Simulations }\end{array}$ & $\begin{array}{r}\text { Coastal region }^{\mathrm{a}} \\
\text { Mean/Std }\end{array}$ & $\begin{array}{r}\text { Remote region }^{\mathrm{a}} \\
\text { Mean/Std }\end{array}$ & $\begin{array}{r}\text { Both regions } \\
\text { Mean/Std }\end{array}$ \\
\hline \multicolumn{5}{|c|}{ Effective radius, cloud water path, and cloud optical thickness } \\
\hline \multirow{6}{*}{$r_{\mathrm{e}}(\mu \mathrm{m})$} & MODIS Terra & $11.3 / 2.2$ & $14.5 / 2.0$ & $13.4 / 2.6$ \\
\hline & AERO & $10.5 / 1.1$ & $12.6 / 1.7$ & $11.9 / 1.8$ \\
\hline & MET & $8.5 / 0.6$ & $8.5 / 0.6$ & $8.5 / 0.6$ \\
\hline & MODIS Aqua & $10.9 / 2.1$ & $13.5 / 1.8$ & $12.7 / 2.3$ \\
\hline & AERO & $9.6 / 1.2$ & $11.8 / 1.7$ & $11.1 / 1.8$ \\
\hline & MET & $8.0 / 0.5$ & $8.2 / 0.6$ & $8.1 / 0.6$ \\
\hline \multirow{6}{*}{$\operatorname{CWP}\left(\mathrm{g} \mathrm{m}^{-2}\right)$} & MODIS Terra & $79.2 / 23.1$ & $99.2 / 20.1$ & $92.8 / 23.1$ \\
\hline & AERO & $83.2 / 32.5$ & $70.5 / 22.5$ & $74.6 / 26.8$ \\
\hline & MET & $100.4 / 40.4$ & $115.7 / 42.9$ & $110.8 / 42.7$ \\
\hline & MODIS Aqua & $58.1 / 19.1$ & $66.9 / 16.9$ & $64.1 / 18.1$ \\
\hline & AERO & $44.9 / 20.9$ & $51.6 / 19.8$ & $49.4 / 20.4$ \\
\hline & MET & $50.1 / 24.1$ & $70.6 / 32.9$ & $64.1 / 31.8$ \\
\hline \multirow{6}{*}{ COT } & MODIS Terra & $10.6 / 2.3$ & $10.4 / 1.8$ & $10.4 / 2.0$ \\
\hline & AERO & $17.7 / 6.5$ & $11.9 / 3.7$ & $13.8 / 5.5$ \\
\hline & MET & 19.2/7.6 & $21.9 / 8.0$ & $21.0 / 8.0$ \\
\hline & MODIS Aqua & $7.9 / 2.1$ & $7.1 / 1.5$ & $7.4 / 1.7$ \\
\hline & AERO & $10.4 / 4.8$ & $9.1 / 2.9$ & $9.5 / 3.7$ \\
\hline & MET & $9.3 / 4.4$ & $13.1 / 6.1$ & $11.9 / 5.9$ \\
\hline \multicolumn{5}{|c|}{ Cloud fraction, cloud base and cloud thickness } \\
\hline \multirow{3}{*}{ Daytime CF (\%) } & GOES-10 & $73.7 / 10.8$ & $76.4 / 5.6$ & $75.4 / 8.2$ \\
\hline & AERO & $79.1 / 8.2$ & $69.5 / 6.5$ & $73.3 / 8.6$ \\
\hline & MET & $79.4 / 8.2$ & $73.9 / 5.5$ & $76.1 / 7.2$ \\
\hline \multirow{3}{*}{ Nighttime CF (\%) } & GOES-10 & $86.5 / 8.5$ & $87.3 / 5.0$ & $87.0 / 6.7$ \\
\hline & AERO & $89.4 / 7.3$ & $80.3 / 5.0$ & $84.0 / 7.9$ \\
\hline & MET & $88.9 / 7.3$ & $84.2 / 5.5$ & $86.1 / 6.7$ \\
\hline \multirow{3}{*}{ Cloud base height (m) } & C-130 & 867 & 1090 & 991 \\
\hline & AERO & 736 & 945 & 828 \\
\hline & MET & 771 & 1075 & 941 \\
\hline \multirow{3}{*}{ Cloud thickness (m) } & C-130 & 280 & 390 & 341 \\
\hline & AERO & 292 & 335 & 316 \\
\hline & MET & 293 & 429 & 369 \\
\hline
\end{tabular}

${ }^{\text {a }}$ Coastal and remote regions are defined as east and west of $78^{\circ} \mathrm{W}$ within the model domain, respectively.

general spatial features observed by the satellite quite well. The domain-average AODs are $0.10 \pm 0.06$ and $0.11 \pm 0.06$ for MODIS and the AERO simulation, respectively. Both the model and observations show that high AOD values (i.e., $>0.2$ ) are located along the coast, especially in a broad band with peak AOD values of approximately $0.3-0.4$ off the northern Peruvian coast. The strong AOD gradient near the coast suggests influences from continental pollution outflow, which is also consistent with the longitudinal variation of aerosol loadings from in-situ instruments (Fig. 3). Alongshore winds associated with high-pressure systems combined with the Andes that form a physical barrier lead to aerosol transport from continental sources such as Santiago, Chile, to the northern coastal region (Huneeus et al., 2006). Dis- crepancies between AERO and the observed AOD include a broader band of enhancements in AERO near the Peruvian coast and a lack of increased AOD values along the northern part of the western lateral boundary. The latter issue is most likely due to an underestimation of oceanic emissions, or overestimations of aerosol dry deposition and/or wet scavenging in this region. Both the model and observations have smaller AOD values farther offshore south of $\sim 23^{\circ} \mathrm{S}$, where the dominant westerly surface flow often brings in relatively clean marine air (Bretherton et al., 2004). 

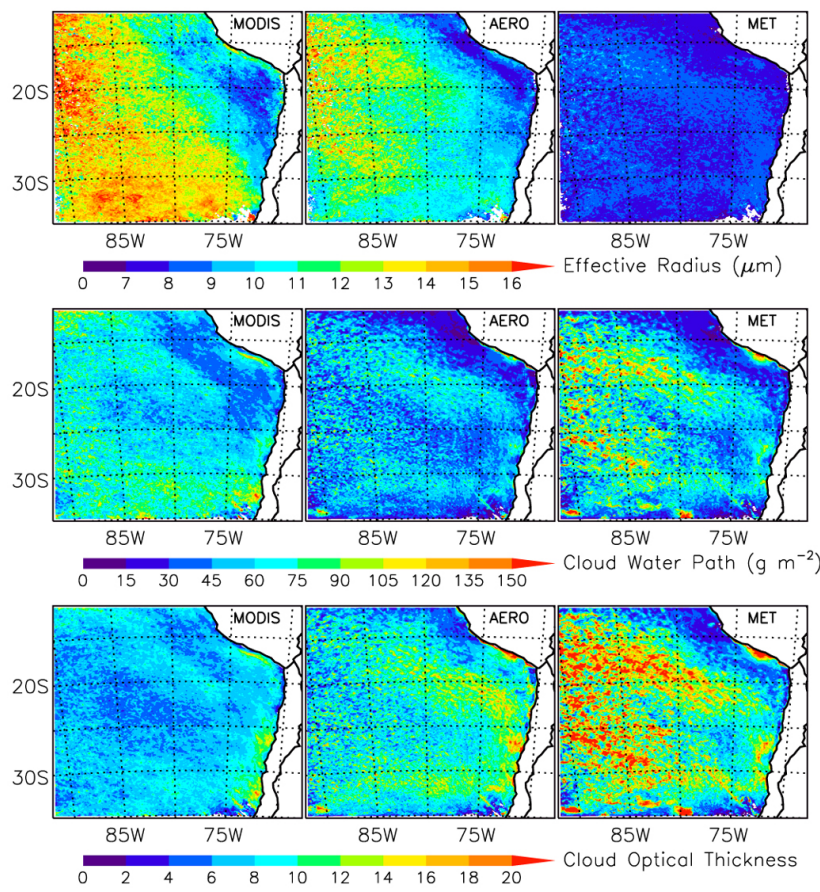

Fig. 7. Effective radius, cloud water path, and cloud optical thickness during the VOCALS-REx period from MODIS (Aqua) retrievals and from the AERO and MET simulations.

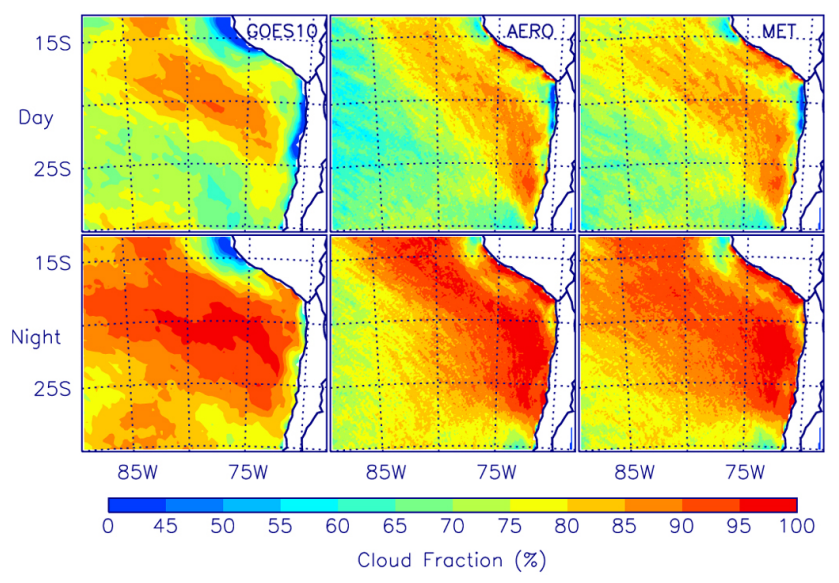

Fig. 8. Mean low cloud fractions during day and night for the VOCALS-REx period retrieved from the GOES-10 (left), and those from the AERO (middle) and MET (right) model simulations.

\subsection{Effective radius, cloud water path, and cloud optical thickness}

Simulated cloud optical properties, which are cloud top effective radius $\left(r_{\mathrm{e}}\right)$, cloud water path (CWP), and cloud optical thickness (COT), are compared against those from MODIS. As shown in Fig. 7 and Table 5, AERO results, in general, agree better with observations than do MET results for these three cloud properties.
MODIS $r_{\mathrm{e}}$ has a distinct longitudinal gradient north of $30^{\circ} \mathrm{S}$ (Fig. 7) with values increasing from $\sim 8 \mu \mathrm{m}$ right off the coast to $>16 \mu \mathrm{m}$ near $90^{\circ} \mathrm{W}$. This spatial distribution is consistent with the AOD gradient shown in Fig. 6. A similar longitudinal $r_{\mathrm{e}}$ gradient is simulated in AERO, though the large $r_{\mathrm{e}}$ south of $30^{\circ} \mathrm{S}$ is not well captured in the model. The domain-average $r_{e}$ (Table 5) values are $\sim 13 \mu \mathrm{m}$ for MODIS observations on the Terra and Aqua, and are 11-12 $\mu \mathrm{m}$ for AERO. In comparison, MET substantially underestimated $r_{\mathrm{e}}(\sim 8-9 \mu \mathrm{m})$, due to the use of the default, constant cloud droplet number concentration of $250 \mathrm{~cm}^{-3}$, which is representative of the conditions near land (Fig. 3). Although reducing the constant $N_{\mathrm{d}}$ of $250 \mathrm{~cm}^{-3}$ to a more representative average droplet number concentration of $150 \mathrm{~cm}^{-3}$ increases domain-average $r_{\mathrm{e}}$ by $14 \%$, the uniform droplet number concentration in MET still limits the spatial and temporal variability of $r_{\mathrm{e}}$.

The domain averages of CWP are 93 and $64 \mathrm{~g} \mathrm{~m}^{-2}$ based on Terra and Aqua satellite retrievals, respectively. The AERO domain-average CWP values are underestimated by $\sim 20 \%$ compared to both satellites. The MET predicted domain averages of CWP are in good agreement with Aqua observations in the afternoon, but are overestimated by $23 \%$ compared to morning observations on the Terra. The CWP spatial variations (Fig. 7) are better simulated in AERO than in MET, and the strong diurnal variation as reflected by the $45 \%$ morning-to-afternoon decrease in domain-average CWP (based on the difference in Terra and Aqua observations) is better simulated in AERO ( $51 \%$ decrease) than in MET ( $73 \%$ decrease). In AERO, the negative bias in CWP over the remote region might be related to the underprediction in droplet number. Low droplet number concentrations due to under-predicted aerosol concentrations result in shorter cloud lifetime. In MET, changing the constant $N_{\mathrm{d}}$ from 250 to $150 \mathrm{~cm}^{-3}$ only reduces CWP by $3 \%$ over the remote region, although the rain rate over this region increases by about $35 \%$; this is due to the very weak drizzle simulated in MET, which is discussed in more detail in Sect. 3.6.

Both AERO and MET overestimate the COT but with a substantially high bias $(\sim 60-100 \%)$ seen in MET (Fig. 7 and Table 5). The doubled COT in MET is related to its near constant small $r_{\mathrm{e}}(10 \mu \mathrm{m})$ and the overestimated CWP that are used in calculating COT (i.e., COT $\sim$ cloud water content $\left./ r_{e}\right)$. The satellite-observed $40 \%$ morning-toafternoon decrease in domain-average COT is also better simulated in AERO ( $\sim 45 \%$ decrease) than in MET ( $~ 75 \%$ decrease). 


\subsection{Cloud fraction, cloud base, and cloud thickness}

Figure 8 shows mean low cloud fractions retrieved from the GOES-10, and those in the AERO and MET during the VOCALS-REx. The presence of low clouds is diagnosed based on the criterion of cloud water mixing ratio exceeding a threshold of $0.01 \mathrm{~g} \mathrm{~kg}^{-1}$ anywhere in a grid column below $700 \mathrm{hPa}$. The resulting cloud fraction for the column is then set to either 0 or 1 . When averaging over the simulation period, the cloud fraction represents the frequency of cloud occurrence.

Satellite observations reveal more cloudiness during the night than during the day with a maximum located near $20^{\circ} \mathrm{S}$ and several degrees in longitude away from the coastline. AERO and MET broadly reproduce the day-night contrast as well as the northeast-southwest gradients in cloudiness as seen in satellite observations. The domain-average low cloud fraction from satellite is $75 \pm 8 \%$ during the day and $87 \pm 7 \%$ during the night (Table 5), which are well predicted ( $<3 \%$ biases) in both AERO and MET simulations with MET having slightly better agreement with observations. While AERO mean cloud fractions are overestimated (3-4\%) over the coastal region, they are underestimated by $7 \%$ over the remote region (i.e., near the south and west boundaries of the domain), as discussed in more detail in Sect. 4.

The near-coast minimum in low cloud fraction resulting from enhanced orographic subsidence associated with synoptic-scale ridging (Toniazzo et al., 2011) is evident in GOES-10 data with minimum values around $15^{\circ} \mathrm{S}$ and south of $20^{\circ} \mathrm{S}$ along the coastline during the day. The nighttime near-coast minimum cloudiness appears at similar locations as in the daytime along the northern Chile coastline but with higher values. Both AERO and MET are able to capture the minimum cloud fractions at these locations but to a smaller spatial extent. An exception is along the coast south of $23^{\circ} \mathrm{S}$ where the simulated cloud fraction exceeds $80 \%$ at night. Between the two minima, both the observed and simulated results show high cloud fractions along the coastline which are likely associated with the dynamical blocking of the surface wind by the southern Peruvian Andes, leading to convergence and a mean upward motion (Garreaud and Munoz, 2005).

Observations and simulations show that cloud thickness increases with distance from the coast. Both AERO and MET modeled cloud thickness are in excellent agreement with the observations $(\sim 340 \mathrm{~m})$, with $\sim 25 \mathrm{~m}$ low and high mean biases (Fig. 9 and Table 5), respectively. While the mean cloud base height from the C-130 over the remote region $(\sim 1100 \mathrm{~m})$ is within the $1000-1200 \mathrm{~m}$ range (median) reported by Bretherton et al. (2010b) for their transition and remote regions, over the coastal region our observed mean cloud base height $(\sim 900 \mathrm{~m})$ is lower than their cloud base height (median, $1000 \mathrm{~m}$ ), which is most likely due to their inclusion of only flight data along $20^{\circ} \mathrm{S}$. Cloud base heights

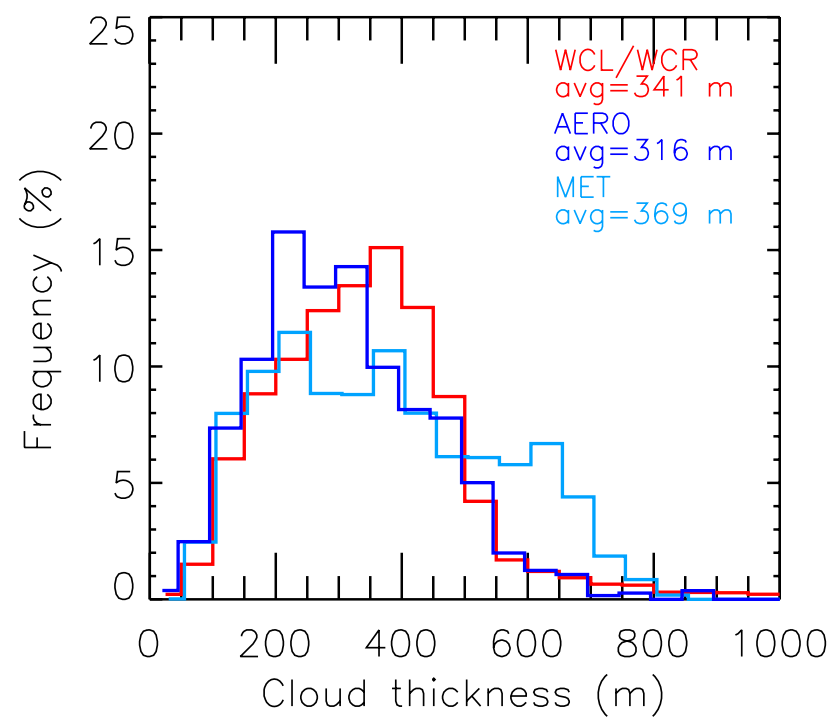

Fig. 9. Histogram of cloud thickness from the Wyoming cloud lidar (WCL) and radar (WCR) observations (red), and from the AERO (blue) and MET (light blue) simulations.

are better predicted in MET than in AERO. The underprediction $(\sim 160 \mathrm{~m})$ of the mean cloud base height in AERO compared to observations on the $\mathrm{C}-130$ is consistent with its low bias (mean bias of $\sim 110 \mathrm{~m}$ ) of MBL heights compared to radiosonde measurements on the RB. AERO does particularly well at simulating the frequency of clouds thicker than about $500 \mathrm{~m}$, while MET overestimates these thicker clouds and underestimates clouds between 300 and $500 \mathrm{~m}$ thick (Fig. 9). In MET, when using a constant $N_{\mathrm{d}}$ of $150 \mathrm{~cm}^{-3}$, cloud thickness is reduced by $20 \mathrm{~m}$ over the remote region, agreeing better with observations.

\subsection{TOA and surface energy fluxes}

Top-of-atmosphere (TOA) outgoing energy fluxes are modulated by water vapor, aerosol, and cloud properties, and surface energy fluxes are linked to SST, wind speed, air-sea temperature, humidity differences, and cloud forcing (de Szoeke et al., 2010). The simulated TOA outgoing SW fluxes are compared against those measured by the CERES onboard the Terra satellite (Fig. 10).

The spatial pattern of satellite TOA outgoing SW fluxes is consistent with the broad feature of the observed daytime cloud fraction shown in Fig. 8. The observed SW fluxes have a band of maximum values ( $>450 \mathrm{~W} \mathrm{~m}^{-2}$ ) nearly parallel to the Peruvian coastline. As shown in Table 6, the domain-average SW flux simulated by AERO $\left(348 \mathrm{~W} \mathrm{~m}^{-2}\right)$ is close to the satellite retrievals, although this is due to compensation between positive and negative biases $(\sim 10 \%)$ over the coastal and the remote regions, respectively. AERO has a band of maximum fluxes roughly collocated with the 
Table 6. Observed and simulated top-of-atmosphere (TOA) outgoing shortwave radiation and surface fluxes.

\begin{tabular}{|c|c|c|c|c|}
\hline $\begin{array}{l}\text { Variable } \\
\text { (Units) }\end{array}$ & $\begin{array}{l}\text { Platform/ } \\
\text { Simulations }\end{array}$ & $\begin{array}{l}\text { Coastal region }^{\mathrm{a}} \\
\text { Mean/Std }\end{array}$ & $\begin{array}{c}\text { Remote region }{ }^{\mathrm{a}} \\
\text { Mean/Std }\end{array}$ & $\begin{array}{c}\text { Both regions } \\
\text { Mean/Std }\end{array}$ \\
\hline \multicolumn{5}{|c|}{ TOA outgoing fluxes } \\
\hline \multirow{3}{*}{$\begin{array}{l}\text { TOA SW } \\
\left(\mathrm{W} \mathrm{m}^{-2}\right)\end{array}$} & MODIS Terra & $360.8 / 69.6$ & $341.2 / 52.5$ & $347.5 / 59.2$ \\
\hline & AERO & $410.4 / 90.8$ & $318.6 / 61.9$ & $348.1 / 84.2$ \\
\hline & MET & $395.8 / 90.9$ & $376.9 / 70.8$ & $383.0 / 78.3$ \\
\hline \multicolumn{5}{|l|}{ Surface fluxes } \\
\hline \multirow{3}{*}{$\begin{array}{l}\text { Sensible heat } \\
\left(\mathrm{W} \mathrm{m}^{-2}\right)\end{array}$} & $\mathrm{RB}$ & $3.0 / 3.2$ & $6.1 / 6.5$ & $4.1 / 4.9$ \\
\hline & AERO & $9.6 / 4.5$ & $15.1 / 6.7$ & $11.6 / 6.0$ \\
\hline & MET & $7.4 / 3.5$ & $10.3 / 5.6$ & $8.5 / 4.6$ \\
\hline \multirow{3}{*}{$\begin{array}{l}\text { Latent heat } \\
\left(\mathrm{W} \mathrm{m}^{-2}\right)\end{array}$} & $\mathrm{RB}$ & $76.5 / 23.9$ & $115.5 / 30.5$ & $90.7 / 32.4$ \\
\hline & AERO & $76.6 / 25.2$ & $140.7 / 34.7$ & $100.0 / 42.4$ \\
\hline & MET & $76.7 / 23.4$ & $149.1 / 39.7$ & $103.1 / 46.2$ \\
\hline \multirow{3}{*}{$\begin{array}{l}\mathrm{SW} \downarrow^{\mathrm{b}} \\
\left(\mathrm{W} \mathrm{m}^{-2}\right)\end{array}$} & $\mathrm{RB}$ & $261.5 / 362.4$ & $227.3 / 311.8$ & $239.8 / 331.5$ \\
\hline & AERO & $257.0 / 356.8$ & $209.5 / 295.1$ & $226.8 / 319.7$ \\
\hline & MET & $222.3 / 336.0$ & $238.2 / 323.9$ & $232.4 / 328.4$ \\
\hline \multirow{3}{*}{$\begin{array}{l}\mathrm{LW} \downarrow^{\mathrm{b}} \\
\left(\mathrm{W} \mathrm{m}{ }^{-2}\right)\end{array}$} & $\mathrm{RB}$ & $373.7 / 21.4$ & $364.9 / 25.6$ & $370.2 / 23.5$ \\
\hline & AERO & $376.0 / 17.9$ & $362.5 / 29.1$ & $371.1 / 23.6$ \\
\hline & MET & $375.2 / 18.2$ & $367.3 / 27.0$ & $372.3 / 22.2$ \\
\hline
\end{tabular}

${ }^{a}$ Coastal and remote regions are defined as east and west of $78^{\circ} \mathrm{W}$ within the model domain, respectively.

$\mathrm{b}$ Downward fluxes.

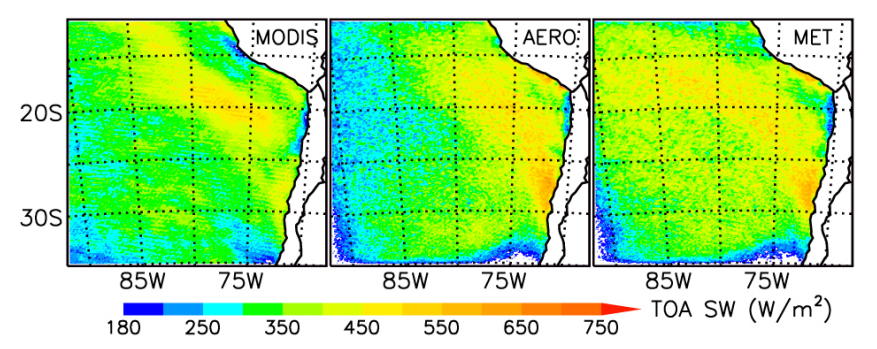

Fig. 10. Top-the-atmosphere (TOA) outgoing shortwave (SW) radiation fluxes measured by the CERES (Terra) and those simulated in the AERO and MET simulations.

observed maximum. But the observed SW minimum along the coast near $15^{\circ} \mathrm{S}$ is not well captured. For this particular region, although AERO simulated COT is smaller than observations (Fig. 7), the impact of this negative bias on outgoing SW fluxes is compensated by overestimations of both AOD (Fig. 6) and cloud fraction (Fig. 8). In AERO, the biases in cloud fraction correlate well with the biases in TOA SW. For example, the low biases near the west boundary correspond to the underestimation of cloudiness in this region. In the MET simulation, TOA SW fluxes are overestimated by $\sim 10 \%$ over both coastal and remote regions. The substantial overprediction of cloud optical thickness in MET (Fig. 8) also contributes to this high bias.
The TOA model-satellite comparison presents a regional view. Alternatively, a sonic anemometer onboard the RB monitored surface fluxes at a high time frequency $(10 \mathrm{~min})$ along the ship track allowing us to examine the associated longitudinal and diurnal variations (Fig. 11). The observed surface fluxes include sensible heat, latent heat, downward shortwave, and downward longwave fluxes (Table 6). Observed sensible heat fluxes are small (domain average of $4 \mathrm{~W} \mathrm{~m}^{-2}$ ) with a weak longitudinal gradient. The mean sensible heat flux is a small negative value at around $80^{\circ} \mathrm{W}$, and de Szoeke (2010) also noted the small sensible heat flux at $80^{\circ} \mathrm{W}$ associated with the relatively small mean sea-air temperature difference at based on a few years of cruise observations along $20^{\circ} \mathrm{S}$. The sensible heat fluxes simulated by AERO and MET are biased high with means of $12 \mathrm{~W} \mathrm{~m}^{-2}$ and $9 \mathrm{~W} \mathrm{~m}^{-2}$, respectively, and have a more distinct increasing trend towards the west. Associated with solar heating of the atmosphere, both observed and simulated sensible heat fluxes have a decreasing tendency from late morning to the afternoon (10:00-17:00 LT), although this decreasing tendency continues to late evening (22:00 LT) in the observations but ends several hours earlier in the simulations.

Both measured and simulated surface latent heat fluxes increase with distance from the coast due mostly to the increase in wind speed. The mean $10 \mathrm{~m}$ wind speed derived using RB measurements and the Coupled Ocean-Atmosphere Response Experiment (COARE 3.0) bulk flux model (Fairall et 
Table 7. Observed and simulated in-cloud and near-surface rain rates.

\begin{tabular}{|c|c|c|c|c|}
\hline $\begin{array}{l}\text { Regions } \\
\text { (Units) }\end{array}$ & $\begin{array}{l}\text { Platform/ } \\
\text { Simulations }\end{array}$ & $\begin{array}{l}\text { Coastal region } \\
\text { Mean/Median }\end{array}$ & $\begin{array}{l}\text { Remote region } \\
\text { Mean/Median }\end{array}$ & $\begin{array}{l}\text { Both Regions } \\
\text { Mean/Median }\end{array}$ \\
\hline \multirow{4}{*}{$\begin{array}{l}\text { In-cloud } \\
\left(\mathrm{mm} \mathrm{day}^{-1}\right)\end{array}$} & C-130 & $0.668 / 0.112$ & $6.891 / 0.396$ & $3.704 / 0.161$ \\
\hline & BAe-146 & $0.462 / 0.000$ & $1.240 / 0.001^{\mathrm{b}}$ & $0.574 / 0.000^{\mathrm{b}}$ \\
\hline & AERO & $0.037 / 0.013$ & $0.163 / 0.052$ & $0.099 / 0.019$ \\
\hline & MET & $0.012 / 0.004$ & $0.052 / 0.013$ & $0.031 / 0.006$ \\
\hline \multirow{4}{*}{$\begin{array}{l}\text { Near surface } \\
\left(\mathrm{mm} \mathrm{day}^{\mathrm{c}}\right)\end{array}$} & C-130 & $0.001 / 0.000$ & $5.175 / 0.002$ & $3.619 / 0.000$ \\
\hline & BAe-146 & $0.001 / 0.000$ & $0.279 / 0.000^{\mathrm{b}}$ & $0.014 / 0.000^{\mathrm{b}}$ \\
\hline & AERO & $0.037 / 0.033$ & $0.069 / 0.053$ & $0.052 / 0.042$ \\
\hline & MET & $0.023 / 0.018$ & $0.059 / 0.044$ & $0.040 / 0.027$ \\
\hline
\end{tabular}

${ }^{a}$ Coastal and remote regions are defined as east and west of $78^{\circ} \mathrm{W}$ within the model domain, respectively. ${ }^{\mathrm{b}}$ The BAe-146 measurement data only covered the east edge of the remote region $\left(78-81^{\circ} \mathrm{W}\right.$ with mean longitude of $\left.79^{\circ} \mathrm{W}\right) .^{\mathrm{c}}$ Below $300 \mathrm{~m}$ for BAe- 146.
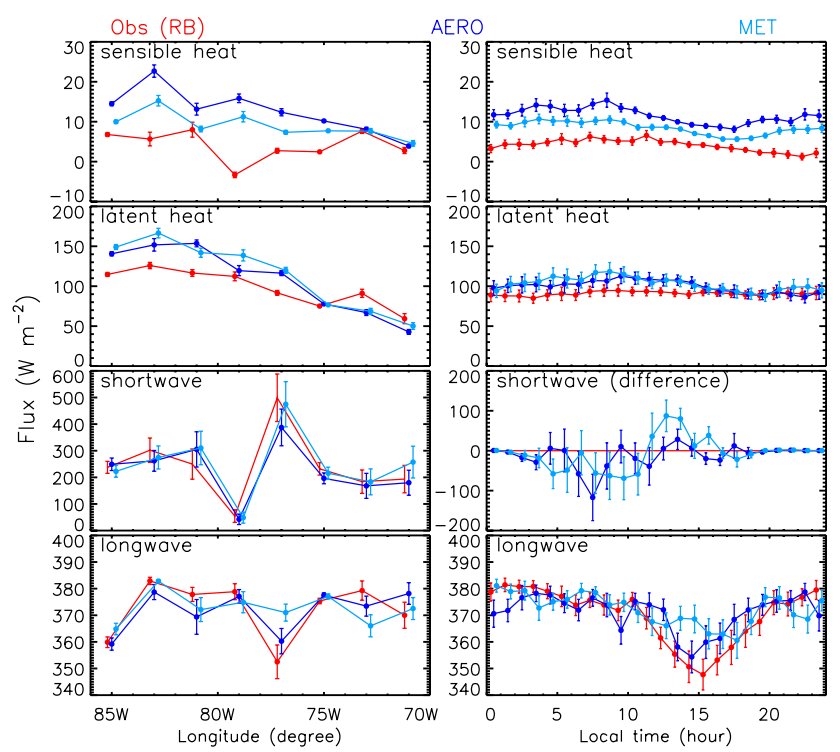

Fig. 11. Longitudinal and diurnal variations of surface fluxes including sensible heat, latent heat, downward shortwave, and downward longwave fluxes, from the sonic anemometer observations on the RB (red) and from the AERO (blue) and MET (light blue) simulations. The diurnal cycle of incoming shortwave fluxes is plotted as the difference between modeled and observed values. The vertical bars indicate $\pm 2 \sigma$, where $\sigma$ is the standard deviation of the mean value given by $\sigma=\sqrt{\operatorname{var}\left(x_{i}\right) / n}$, where $\operatorname{var}\left(x_{i}\right)$ is the variance of data used for the averaging, and $\mathrm{n}$ is the number of the data points. Note that due to the large variability in some parameters, $\sigma$ is not represented as the square root of the variance as in other figures.

al., 2011) increases from $4.8 \mathrm{~m} \mathrm{~s}^{-1}$ over the coastal region to $8.2 \mathrm{~m} \mathrm{~s}^{-1}$ over the remote region. The observed surface latent heat flux has a mean value of $91 \mathrm{~W} \mathrm{~m}^{-2}$. The mean latent heat flux from AERO $\left(100 \mathrm{~W} \mathrm{~m}^{-2}\right)$ shows a slight improvement from that $\left(103 \mathrm{~W} \mathrm{~m}^{-2}\right)$ of MET. The observed latent heat fluxes do not have a distinct diurnal variation; the simulated latent heat has biases which peak in the early morning.
The mean downward SW flux from the AERO agrees within $2 \%$ with observations over the coastal region, and is $\sim 8 \%$ lower over the remote region. The MET simulation underestimates SW fluxes by $\sim 15 \%$ over the coastal region, but overpredicts by $5 \%$ over the remote region. The apparent better-predicted SW fluxes over the coastal region in AERO compared to MET indicate better-predicted daytime cloud cover along the path of the ship in AERO over this region. The diurnal variation of incoming SW fluxes in Fig. 11 is plotted as differences between modeled and observed values due to the large diurnal cycle. Both simulations tend to underpredict SW in the morning; AERO shows apparent better predictions than does MET in the afternoon. The analysis shown here is a direct comparison of observed and simulated data in corresponding times and locations and does not account for the large instant biases in SW due to prediction biases in instantaneous cloud field. Therefore, given this strict comparison, the results are quite good.

Predicted downward longwave fluxes and observations are in good agreement with mean differences of less than $1 \mathrm{~W} \mathrm{~m}^{-2}$. The observed downward longwave fluxes have a distinct diurnal variation with higher values $\left(\sim 380 \mathrm{~W} \mathrm{~m}^{-2}\right)$ at night and a minimum $\left(\sim 350 \mathrm{~W} \mathrm{~m}^{-2}\right)$ in the afternoon (15:00 LT). The AERO simulates a slightly better variation than does the MET during the day. The diurnal and longitudinal variations of the surface downwelling SW and LW fluxes are strongly associated with the corresponding variations in clouds.

\subsection{Rain rate}

Rain rate in marine stratocumulus is tightly connected to both cloud macro and microphysical properties, and rain processes exert important feedbacks to the MBL through redistribution of heat and moisture. Modeled rain rates are compared against those derived from measurements by $2 \mathrm{D}-\mathrm{C}$ probes onboard the C-130 and BAe-146 aircrafts. Mean and 
median in-cloud and near-surface rain rate values are presented in Table 7. In-cloud rain rates are averaged over the in-cloud flight legs with various depths in the cloud layer. The in-cloud and near-surface rain rates from the C-130 and BAe-146 agree within $30 \%$ over the coastal region with the differences most likely associated with different particle size detection ranges of the instruments. This good agreement provides additional confidence in the derived rain rates from both $2 \mathrm{D}-\mathrm{C}$ probes in this study. The rain rates over the remote region from the BAe-146 are much smaller than those measured by the $\mathrm{C}-130$ and are not representative of the entire remote region since the BAe-146 2D-C measurements only covered a small longitudinal range over the east edge of the remote region $\left(78-81^{\circ} \mathrm{W}\right.$ with mean longitude of $\left.79^{\circ} \mathrm{W}\right)$. Therefore, the rain rate discussion that follows is based entirely on C-130 observations.

Noticeable longitudinal gradients exist in observed incloud and near-surface rain rates $(\sim 200 \mathrm{~m}$ above the ocean surface). Observed average in-cloud rain rates increase by about 10 -fold ( 0.668 vs. $\left.6.891 \mathrm{~mm} \mathrm{day}^{-1}\right)$ from the coastal to the remote region (Table 7). Overall, the longitudinal variations in rain rates are captured in model simulations but predicted rain rates are about an order of magnitude smaller than the observed values within the cloud layer (Fig. 12 and Table 7). Our calculated mean rain rates are higher than those of Bretherton et al. (2010b) derived from a different 2D-C probe and the maximum radar reflectivity. However, the median values of our in-cloud and near-surface rain rates agree reasonably well with those of the radar derived rain rates in Bretherton et al. (2010b). We used the precipitation sizing data observed using the $25 \mu \mathrm{m}$ resolution $2 \mathrm{D}-\mathrm{C}$ probe which is more reliable than the other $10 \mu \mathrm{m}$ resolution $2 \mathrm{D}-\mathrm{C}$ probe on the C-130, of which the true resolution was later found unstable (A. Schanot, personal communication, 2010). AERO produces higher rain rates than the MET, with the AERO median rain rates being generally close to the 75 th percentile of MET, resulting in closer agreement with observations for AERO.

In the near-surface layer, drizzle was barely observed over the coastal region. Over the remote region although the observed mean near-surface rain rate is $\sim 75 \%$ of the in-cloud value, the median rain rate in near-surface layer is drastically smaller than the in-cloud value $\left(0.002\right.$ vs. $\left.0.396 \mathrm{~mm} \mathrm{day}^{-1}\right)$. The observed strong near-surface/in-cloud contrast seen in median rain rates but not in the means could be explained by the skewed distribution of rain rates. Light rain occurs more frequently in the SEP stratocumulus, dominates the median value, and is associated with smaller mean raindrop size and relatively high evaporation rates below clouds. In contrast, the mean precipitation rate is dominated by relatively heavier rain, which is associated with larger mean raindrop size and hence relatively lower evaporation rates below clouds. In both simulations, the near-surface/in-cloud rain rate contrasts are not well represented, although these observed contrast might be larger than in reality due to a $62.5 \mu \mathrm{m}$ lower

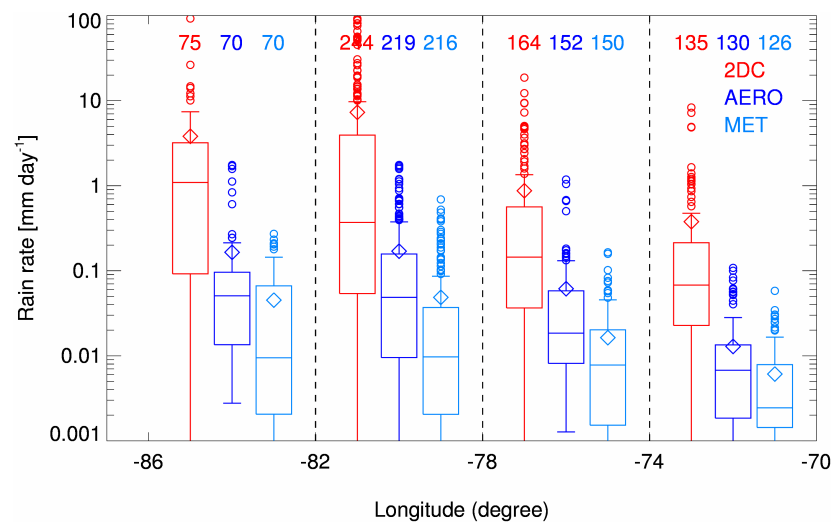

Fig. 12. Box and whisker plots of longitude-binned rain rates from in-cloud measurements (red) by a 2D-C probe onboard the C-130 aircraft and from corresponding in-cloud values in the AERO (blue) and MET (light blue) simulations. The bottom and top of the box are 25 th and 75 th percentiles. The median is shown inside the box. The 10th and 90th percentiles are shown by the dash outside the box. The open circles indicate outliers (lower than 10th or higher than 90th percentiles). The diamonds show the mean over all legs in each longitude bin. The numbers on the top indicate the number of data points used to produce the box and whisker plot.

raindrop cutoff diameter in measurements. Evaporation below cloud base might shrink raindrops to sizes smaller than $62.5 \mu \mathrm{m}$ at the near-surface layer, which could not be detected by the $2 \mathrm{D}-\mathrm{C}$ probe.

In addition, the model did not reproduce the large variability in observed rain rates. The observed rain rates are as high as $100 \mathrm{~mm} \mathrm{day}^{-1}$ on some flight legs, as indicated by the outliers (red circles in Fig. 12), yet the modeled drizzle rates barely exceed $2 \mathrm{~mm}_{\text {day }}{ }^{-1}$. This is most likely a model resolution issue. The rain rates derived from flight data were averaged over about $9 \mathrm{~km}$ flight distance, which is comparable to our model horizontal grid size. However, the WRF model is known to actually resolve processes at scales about 7 times the horizontal grid spacing (Skamarock, 2004). Higher vertical and horizontal resolution simulations will be conducted in a follow-on study to explore this resolution issue.

\section{Discussion}

Observations show that the MBL is more well-mixed and capped with a stronger temperature inversion over the coastal region $\left(70-78^{\circ} \mathrm{W}\right)$ than over the remote region $\left(78-88^{\circ} \mathrm{W}\right)$. The simulated mean MBL temperature and humidity, in general, are in good agreement with the observed values over the remote region, but larger biases are found over the coastal region in both AERO and MET simulations during early November when the MBL top inversion is weaker and the vertical variability of humidity is large. 
The predicted MBL depth has a $130 \mathrm{~m}$ reduction when aerosol-cloud interactions are included in the model simulation (i.e., in AERO). Processes at different scales influence MBL depths over the SEP. For example, large-scale subsidence tends to suppress the growth of MBL; the local change of MBL depth with time may be affected by the horizontal advection of temperature and moisture at the top of the MBL (Rahn and Garreauh, 2010); active turbulent mixing corresponds to a higher MBL, and entrainment deepens and dries the MBL (Wood and Bretherton, 2004; Zuidema et al., 2009). Lower MBL depths in AERO compared to MET indicate the active role of aerosol and aerosol-cloud interactions in modifying those MBL processes. The horizontally and temporally averaged subsidence rate in the layers above the MBL is consistently stronger in AERO than in MET; at $850 \mathrm{hPa}$, the average subsidence rate is $0.24 \mathrm{~cm} \mathrm{~s}^{-1}$ in AERO, which is about $0.015 \mathrm{~cm} \mathrm{~s}^{-1}$ higher than in MET. The AERO-predicted MBL top entrainment rate $\left(0.67 \mathrm{~cm} \mathrm{~s}^{-1}\right)$ is about $24 \%$ smaller compared to that of the MET simulation $\left(0.88 \mathrm{~cm} \mathrm{~s}^{-1}\right)$. The entrainment rate was estimated using Eq. (4) of Yang et al. (2009) with 5-min model outputs of tracer concentrations. It is worth noting that the estimated entrainment rate is larger than the nighttime entrainment rate $\left(0.4 \mathrm{~cm} \mathrm{~s}^{-1}\right)$ estimated by Yang et al. (2009) using budget analysis of measured DMS during the VOCALS-REx. This is very likely due to vertical resolution near cloud top and in the inversion layer. LES model simulations show entrainment is very sensitive to the vertical resolution and generally use finer resolution (e.g., $5 \mathrm{~m}$ in Bretherton et al., 2010a) than in our simulations. However, there is no reason to expect that the bias (relative to the Yang et al. estimate) would differ significantly between the AERO and MET simulations, so the $24 \%$ difference in entrainment rates between the two simulations should be meaningful. The $130 \mathrm{~m}$ lower MBL depth in AERO, compared to MET, could thus be explained by the entrainment and somewhat stronger mean subsidence in AERO. The AERO, compared to MET, also produces improved moisture and temperature gradients in the capping inversion layer. The strengthening of the inversion near the coast by including aerosol in the model is likely due to the atmospheric diabatic heating induced by the direct effect of the absorbing aerosols and the resulting semi-direct effect of enhancing cloud evaporation (Matsui et al., 2006; Dunion and Velden, 2004). Particularly, compared to the MET, the stronger inversion in the AERO leads to weaker entrainment and suppresses the vertical growth of the MBL.

Simulated MBL aerosol is evaluated against observations in number, mass composition, and optical properties. The observed strong gradient in accumulation mode $(0.16-2.69 \mu \mathrm{m})$ aerosol number concentrations near the coast over the SEP region is also predicted reasonably well in the AERO simulation. The predicted accumulation-mode aerosol number has a low bias of about $\sim 30 \%$, which is in rather good agreement for simulating aerosol number. The longitudinal variation in droplet number, in general, corresponds to the spatial variation in aerosols. Consistent with the underestimation of accumulation mode aerosol, the cloud droplet number concentrations are also too low.

The well-simulated variability of $N_{\mathrm{d}}$ during the polluted and clean episodes illustrate the capability of the model with prognostic aerosols in simulating variations of aerosol and clouds at daily/synoptic scales, and thus the model is suitable for studies at such scales.

Non-sea-salt sulfate is the dominant aerosol species in submicron mass concentrations over both coastal and remote regions within the SEP MBL. It is tempting to attribute the larger underprediction in sulfate mass over the remote region compared to the coastal region (35-62\% vs. $11-37 \%$ ) to the underprediction of secondary sulfate produced from DMS oxidation. However, further investigation does not support this explanation. The mean AERO-predicted DMS air mixing ratio is approximately a factor of 3 higher than the mean RB observations (Table 3) which can be partially explained by the $\sim 71 \%$ overestimation of the DMS ocean-toatmosphere transfer velocity $\left(K_{\mathrm{W}}\right)$. The high bias in $K_{\mathrm{W}}$ occurs mainly at higher wind speeds (not shown), consistent with Blomquist et al. (2006). Another source of error is the setting of a constant oceanic DMS as in the VOCA model intercomparison specifications. However, given the transfer velocity overestimate, the prescribed seawater DMS would have to be unrealistically low to cause the sulfate bias. Despite the high predicted DMS levels relative to observations, predicted $\mathrm{MBL} \mathrm{SO}_{2}$ mixing ratios are underestimated (11.8 vs. $27.8 \mathrm{pptv}$ ) over the remote region. Sensitivity tests show that most of the emitted DMS converts to $\mathrm{SO}_{2}$, which then converts to sulfate primarily via aqueous phase cloud chemistry reactions. Speeding up the DMS gas-phase chemistry lowers DMS air concentrations but has little impact on sulfate (not shown). Therefore, the underestimation of sulfate is unlikely due to modeled DMS emissions or oxidation. An alternate explanation is that wet removal of sulfate, particularly that just formed by cloud chemistry, is too rapid in the model, and this needs further investigation. The underestimation of sulfate near the coast is likely due to low biases in continental emissions and/or transport biases.

The simulated chloride and sodium mass concentrations for diameters below $1.5 \mu \mathrm{m}$ are in good agreement with observations from the PILS on the G-1, but the supermicron concentrations are approximately double the observations from the ICS on the RB. This suggests possible errors in the predicted sea-salt size spectrum for larger sizes $(>1.5 \mu \mathrm{m})$, which could also affect the modeled dry deposition. More detailed observed sea-salt size distributions are not available; however, the substantial overestimation in the mass demonstrates the need to further evaluate the sea-salt emission scheme used in WRF-Chem to bring mass concentrations and sizes of sea-salt particles into better agreement with the observations. Compared with PILS observations, chloride deficit is well simulated by the AERO, but nitrate was underpredicted by $\sim 50 \%$. The low mean nitrate amount 
in AERO compared to that of PILS observations indicates a possible low bias in anthropogenic precursor emissions of nitrate.

Anthropogenic outflow and synoptic influences on the spatial variation of the mean AOD field are apparent in both satellite observations and simulations. Simulated AOD values agree well with observations on a domain-average basis, although the near-coast enhancements cover a broader area in the model. The high AOD close to the coast is consistent with the predicted aerosol mass along the G-1 flight tracks that was also somewhat higher than those of the C-130 (Fig. 5).

Despite the inevitable uncertainties in the predicted aerosol mass, composition, and size distribution, cloud optical properties are, in general, better simulated in the AERO than in the MET. In the simulations, the location of high aerosol loading mostly corresponds to low CWP over the coast. The aerosol semi-direct effect is one of the possible reasons for the low CWP with high aerosol concentrations (Matsui et al., 2006). Higher cloud droplet numbers in a polluted environment are associated with a more stable atmosphere (Painemal and Zuidema, 2010; and references therein); Despite the highly complex relationship between drizzle and stability, the LES modeling study by Jiang et al. (2002) showed that, relative to a clean environment, where cooling from drizzle evaporation below cloud base destabilizes the slice of layer below cloud base (relative to the surface), drizzle inhibition in polluted air leads to a relatively stable atmosphere and a less effective supply of moisture from the surface to cloud layer, resulting in low CWP.

Inclusion of interactive aerosols in AERO also leads to better simulated cloud top optical properties $\left(r_{\mathrm{e}}, \mathrm{CWP}\right.$, and COT).

Predicted period-mean cloud fields from both simulations are in good agreement with the satellite observations. While AERO slightly overestimates (3-4\%) over the coastal region, cloud fractions are underestimated by $\sim 7 \%$ over the remote areas which is mainly due to the underestimation of cloudiness close to the west and south boundaries of the model domain. The underprediction of cloud fraction over the west and south boundaries also results in a negative bias in TOA SW compared to satellite observations. In AERO, small cloud droplet number concentrations near west and south boundaries allow droplets to grow into large raindrops which deplete the available liquid water leading to underestimation in cloud fraction in these areas. The predicted cloud thickness in AERO is in excellent agreement with the radar/lidar observations, which is consistent with better-simulated CWP variations in AERO. The underprediction $(\sim 160 \mathrm{~m})$ of the mean cloud base/top height in AERO compared to observations on the C-130 platform is consistent with its underprediction (mean low bias of $110 \mathrm{~m}$ ) in predicted MBL heights compared to radiosonde measurements on the RB.

Both AERO and MET show near-coast cloud fraction minima over similar locations as observed but to a smaller spatial extent, with the exception along the coast south of about $23^{\circ} \mathrm{S}$ where the simulated cloud fraction exceeds $80 \%$ at night. The fairly well simulated near-coast clear skies in MET indicates that the near-coast cloud clearance is a largely synoptic-induced event as concluded by Toniazzo et al. (2011) and references therein.

The TOA outgoing SW fluxes manifest the cloud albedo effect, and are closely related to cloud fraction and cloud top $r_{\mathrm{e}}$. The domain-average SW flux simulated in AERO is similar to the observed $\left(347 \pm 59 \mathrm{~W} \mathrm{~m}^{-2}\right)$, although this is the result of a positive bias $\left(49 \mathrm{~W} \mathrm{~m}^{-2}\right)$ over the coastal region and a negative bias $\left(-23 \mathrm{~W} \mathrm{~m}^{-2}\right)$ over the remote region. The positive bias in albedo over the coastal region in AERO is related to the overprediction of the near-coast cloud fraction. The negative biases near the west boundary in the AERO are related to the aforementioned underestimation of cloud fraction near west and south boundaries. MET overestimates TOA SW by $35 \mathrm{~W} \mathrm{~m}^{-2}$ over both coastal and remote regions. In MET, the overprediction of cloud optical thickness in the SW scheme also contributes to the high bias in mean cloud albedo.

Both observed and simulated sensible and latent heat fluxes increase towards the west. The near-surface air in the remote region is warmer (by $0.5 \mathrm{~K}$, on average) and more humid (by $0.6 \mathrm{~g} \mathrm{~kg}^{-1}$, on average) than the coastal region (statistically significant with $98 \%$ confidence level) according to the observations on the ship platform. This observed gradient is consistent with the conclusion from de Szoeke et al. (2010) using multi-year cruise observations along $20^{\circ} \mathrm{S}$. Similar differences $\left(0.8 \mathrm{~K}\right.$ and $\left.0.3 \mathrm{~g} \mathrm{~kg}^{-1}\right)$ between the two regions are also simulated in the model. These differences in near-surface temperature and specific humidity and the gradients in SST and wind speed (Table 3) all contribute to the seen longitudinal gradients in sensible and latent heat fluxes in both RB observations and model simulations. Both sensible and latent heat fluxes are overpredicted by the AERO and MET. Sensible heat fluxes are small but they are significantly overpredicted in both simulations over the remote region. The mean surface latent heat fluxes are overpredicted by $\sim 20 \%$ in AERO and by $\sim 30 \%$ in MET. The mean SSTs in the simulations are in close agreement with observations over the remote region, thus are unlikely to be responsible for the higher predicted biases (Fig. 11) over this region; although the mean SSTs are biased low (by $0.3 \mathrm{~K}$ ) over the coastal region (Table 3). For both AERO and MET simulations, the positive mean bias $\left(0.6 \mathrm{~m} \mathrm{~s}^{-1}\right)$ in surface wind speed partially explains the positive biases in latent and sensible heat fluxes over the remote region. The cold bias (mean biases of $\sim 0.5 \mathrm{~K}$ for both simulations) in the lowest model layer also contributes to the mean positive biases in simulated sensible heat. However, the near-surface humidity bias (mean biases of $\sim 0.5 \mathrm{~g} \mathrm{~kg}^{-1}$ for both simulations) seems to contradict the positive mean bias in predicted latent heat fluxes. There are still unexplained modelmeasurement differences in surface sensible and latent heat 
fluxes that are likely to be associated with some limitations of the surface layer scheme (the Monin-Obukhov similarity theory scheme in WRF) when applied over the SEP. This requires further investigation. Note that this scheme has been improved recently (Jimenez et al., 2011) and is planned to be released to the WRF community in the near future (P. A. Jimenez, personal communication, 2011), although the revised scheme was only evaluated over land. Surface incoming longwave fluxes have better agreement with observations over the coastal region and in the overall diurnal cycles in AERO. Downwelling SW fluxes are better predicted over the coast region and in the afternoon in AERO.

The simulated in-cloud drizzle rates have similar longitudinal gradients as seen in the observations, although they are significantly underestimated and have low variability. Without a shallow convection scheme, the model will not be able to reproduce the observed heavier rains such as those $>100 \mathrm{~mm} \mathrm{day}^{-1}$. Even with a shallow convection scheme, the model would probably not be able to produce correct heat and moisture transports that are crucial in sustaining the organized precipitating stratocumulus clouds, since the PBL parameterization is not designed to handle open-cell dynamics. In addition, our $9 \mathrm{~km}$ horizontal spacing is inadequate in resolving open cellular cloud structures, although the vertical model resolution of $50 \mathrm{~m}$ is comparable to the $30 \mathrm{~m}$ used in the large-eddy simulation (LES) in Wang and Feingold (2009a, b). Observations (e.g., Wood et al., 2011a) and LES simulations (e.g., Wang and Feingold, 2009a, b) found that strongly precipitating stratocumulus clouds typically consist of narrow open-cell walls of less than $10 \mathrm{~km}$ in width which is much smaller than our model's effective resolution $(\sim 7 \Delta x)$. Therefore, horizontal resolution are also likely to be responsible for the inability of our simulations to reproduce correct precipitation variability. Future studies will be conducted to investigate this resolution-related issue with an ultimate goal of improving the parameterization of stratocumulus-related subgrid scale processes in climate models.

\section{Summary and conclusion}

This study assesses the ability of the recent chemistry version (v3.3) of the Weather Research and Forecasting (WRF-Chem) model to simulate boundary layer structure, aerosols, stratocumulus clouds, and energy fluxes over the Southeast Pacific ocean. Measurements from the VAMOS Ocean-Cloud-Atmosphere-Land Study Regional Experiment (VOCALS-REx) and satellite retrievals (i.e., products from the MODerate resolution Imaging Spectroradiometer (MODIS), Clouds and the Earth's Radiant Energy System (CERES), and GOES-10) are used for the assessment. The Morrison double-moment microphysics scheme is newly coupled with interactive aerosols in WRF-Chem. This study demonstrates the effectiveness of the new ca- pability and forms the foundation for future studies using the coupled scheme. The 31-day (15 October-16 November 2008) WRF-Chem simulation with aerosol-cloud interactions (AERO hereafter) is also compared to a simulation (MET hereafter) with fixed cloud droplet number concentrations in the microphysics scheme and simplified cloud and aerosol treatments in the radiation scheme. The wellpredicted aerosol quantities, such as aerosol number, mass composition and optical properties, and the inclusion of full aerosol-cloud couplings lead to significant improvements in many features of the predicted stratocumulus clouds: cloud optical properties and microphysical properties such as cloud top effective radius, cloud water path, and cloud optical thickness, and cloud macrostructure such as cloud depth and cloud base height. In addition to accounting for the aerosol direct and semi-direct effects, these improvements feed back to the prediction of boundary-layer characteristics and energy budgets. Particularly, inclusion of interactive aerosols in AERO strengthens the temperature and humidity gradients within the capping inversion layer and lowers the marine boundary layer depth by $130 \mathrm{~m}$ from that of the MET simulation. These differences are associated with weaker entrainment and stronger mean subsidence in AERO. Mean TOA outgoing shortwave fluxes, surface latent heat, and surface downwelling longwave fluxes are in better agreement with observations in AERO, compared to the MET simulation.

The well-simulated timing and outflow patterns of polluted and clean episodes demonstrate the model's ability to capture daily/synoptic scale variations of aerosol and cloud properties, and suggest that the model is suitable for studying atmospheric processes associated with pollution outflow over the ocean.

The simulations conducted as part of this study were submitted to the VOCALS modeling assessment that will be published in the near future. This paper supplements the upcoming broad assessment by showing links between aerosols and clouds, and providing additional insights into the capability of current regional model with interactive aerosols in predicting aerosol and cloud fields over the SEP region. Our findings as presented in this paper will help explain some of the differences among model results in the assessment. Our evaluation also implies the importance of treating aerosol-cloud-radiation interactions in climate modeling. Results from this study illustrate that an accurate representation of aerosol properties, variations, their interactions with clouds, and impacts to radiation through direct and firstindirect effects in models could improve the MBL structure, TOA/surface energy fluxes, and cloud properties in regional scale simulations; similar improvements are expected in climate models with aerosol-cloud-radiation coupling. This study compared two extreme cases: one with prognostic aerosol and aerosol-cloud-radiation couplings, and the other with a cloud droplet concentration that is fixed in space and time, and simplified cloud and aerosol treatments in the radiation scheme. It might be possible to reasonably capture 
average spatial and temporal variability of some microphysical variables using prescribed temporal/spatial gradients of droplet concentrations or background aerosol with simplified cloud and aerosol treatments in the radiation scheme.

The overall performance of the model in simulating mesoscale aerosol-cloud interactions associated with marine stratocumulus is encouraging. Future work includes model development to improve the DMS emission scheme, further investigations of the underprediction of $\mathrm{MBL} \mathrm{SO}_{2}$ and the overestimation of supermicron sea salt, etc. This study focused on MBL characteristics rather than large-scale dynamics, and additional research is needed to investigate the impacts of parameterized mixing, entrainment, and large-scale dynamics on the simulated aerosol, clouds, and precipitation. This study is the necessary first step to form the foundation for a planned range of future studies using a similar model configuration. Simulations at smaller horizontal grid spacings will be presented in a follow-up study regarding the sensitivity of predicted aerosols, clouds, and their dependence on spatial resolution. In addition, multiple aerosolcloud equilibrium regimes (e.g., Baker and Charlson, 1990) over the southeastern Pacific Ocean will be investigated using WRF-Chem in the near future.

Acknowledgements. Funding for this research has been provided by the US National Oceanic and Atmospheric Administration (NOAA) Atmospheric Composition and Climate Program (NA10AANRG0083/56091). Pacific Northwest National Laboratory is operated by Battelle Memorial Institute for the US Department of Energy under Contract No. DE-AC05-76RL01830. $\mathrm{RB}$ and C-130 measurements were obtained from the VOCALS data archive of NCAR/EOL, which is sponsored by the US National Science Foundation. We acknowledge the NCAR Research Aviation Facility for providing the measurements on the C-130. We thank the UK Natural Environment Research Council (NERC) for funding the VOCALS UK contingent to the project (grant ref: NE/F019874/1) and the NERC Facility for Airborne and Atmospheric Measurement (FAAM) and Direct Flight and Avalon for operational support of the BAe-146 aircraft. Participation of the DOE G-1 aircraft in VOCALS-Rex was supported by the former Atmospheric Sciences Program (now the Atmospheric System Research Program) within the DOE Office of Biological and Environmental Research. We also acknowledge D. Leon and the staff of University of Wyoming for the radar/lidar derived cloud top and cloud base data, G. Vali for the rain rate derivation scheme, C. Duli for the helpful discussion regarding satellite data quality, S. Abel and G. Allen for the low cloud fraction data retrieved from the GOES-10, C. Fairall and L. Bariteau for surface flux data, B. J. Huebert for DMS data, A. Schanot and J. Jensen for guidance of the 2D-C measurement data usage, S. de Szoeke, S. Yuter, and C. Fairall for Rawinsonde data, T. Bates for the aerosol composition data on the RB and guidance in data usage, S. Howell and L. Shank for the aerosol composition data on the C-130, A. Bandy for gas phase $\mathrm{SO}_{2}$ measurements on $\mathrm{C}-130$. We also thank the many scientists who participated to generate VOCALS field campaign dataset. MODIS and CERES data were obtained from the NASA Langley Research Center Atmospheric Science Data Center. We acknowledge NSF (grant number 0748012) and Fondecyt Iniciacion (project 11090084) for support of the VOCA emission. Some of the analyses were completed using the Aerosol Modeling Testbed tools developed as part of the Aerosol Climate Initiative supported by Laboratory Directed Research Development program at Pacific Northwest National Laboratory.

Edited by: R. Wood

\section{References}

Abel, S. J., Walters, D. N., and Allen, G.: Evaluation of stratocumulus cloud prediction in the Met Office forecast model during VOCALS-REx, Atmos. Chem. Phys., 10, 10541-10559, doi:10.5194/acp-10-10541-2010, 2010.

Albrecht, B. A.: Aerosols, Cloud Microphysics, and Fractional Cloudiness, Science, 245, 1227-1230, 1989.

Allen, G., Coe, H., Clarke, A., Bretherton, C., Wood, R., Abel, S. J., Barrett, P., Brown, P., George, R., Freitag, S., McNaughton, C., Howell, S., Shank, L., Kapustin, V., Brekhovskikh, V., Kleinman, L., Lee, Y.-N., Springston, S., Toniazzo, T., Krejci, R., Fochesatto, J., Shaw, G., Krecl, P., Brooks, B., McMeeking, G., Bower, K. N., Williams, P. I., Crosier, J., Crawford, I., Connolly, P., Allan, J. D., Covert, D., Bandy, A. R., Russell, L. M., Trembath, J., Bart, M., McQuaid, J. B., Wang, J., and Chand, D.: South East Pacific atmospheric composition and variability sampled along $20 \mathrm{~S}$ during VOCALS-REx, Atmos. Chem. Phys., 11, 5237-5262, doi:10.5194/acp-11-5237-2011, 2011.

Baker, M. B. and Charlson, R. J.: Bistability of CCN Concentrations and Thermodynamics in the Cloud-topped BoundaryLayer, Nature, 345, 142-145, 1990.

Blomquist, B. W., Fairall, C. W., Huebert, B. J., Kieber, D. J., and Westby, G. R.: DMS sea-air transfer velocity: Direct measurements by eddy covariance and parameterization based on the NOAA/COARE gas transfer model, Geophys Res Lett, 33, L07601 doi:10.1029/2006g1025735, 2006.

Bretherton, C. S., Uttal, T., Fairall, C. W., Yuter, S. E., Weller, R. A., Baumgardner, D., Comstock, K., Wood, R., and Raga, G. B.: The EPIC 2001 stratocumulus study, B. Am. Meteorol. Soc., 85, 967-977, 10.1175/BAMS-85-7-967, 2004.

Bretherton, C. S., Uchida, J., and Blossey, P. N.: Slow manifolds and multiple equilibria in stratocumulus-capped boundary layers, J. Adv. Model. Earth Syst., 2, 14, doi:10.3894/JAMES.2010.2.14, 2010a.

Bretherton, C. S., Wood, R., George, R. C., Leon, D., Allen, G., and Zheng, X.: Southeast Pacific stratocumulus clouds, precipitation and boundary layer structure sampled along $20^{\circ} \mathrm{S}$ during VOCALS-REx, Atmos. Chem. Phys., 10, 10639-10654, doi:10.5194/acp-10-10639-2010, 2010b.

Chapman, E. G., Gustafson Jr., W. I., Easter, R. C., Barnard, J. C., Ghan, S. J., Pekour, M. S., and Fast, J. D.: Coupling aerosolcloud-radiative processes in the WRF-Chem model: Investigating the radiative impact of elevated point sources, Atmos. Chem. Phys., 9, 945-964, doi:10.5194/acp-9-945-2009, 2009.

Clarke, A. D., Owens, S. R., and Zhou, J. C.: An ultrafine seasalt flux from breaking waves: Implications for cloud condensation nuclei in the remote marine atmosphere, J. Geophys. ResAtmos., 111, D06202, doi:10.1029/2005jd006565, 2006.

de Szoeke, S. P., Fairall, C. W., Wolfe, D. E., Bariteau, L., and Zuidema, P.: Surface Flux Observations on the Southeastern Tropical Pacific Ocean and Attribution of SST Errors in Cou- 
pled Ocean-Atmosphere Models, J. Climate, 23, 4152-4174, doi:10.1175/2010jcli3411.1, 2010.

De Carlo, P. F., Kimmel, J. R., Trimborn, A., Northway, M. J., Jayne, J. T., Aiken, A. C., Gonin, M., Fuhrer, K., Horvath, T., Docherty, K. S., Worsnop, D. R., and Jimenez, J. L.: Fielddeployable, high-resolution, time-of-flight aerosol mass spectrometer, Anal. Chem., 78, 8281-8289, doi:10.1021/ac061249n, 2006.

Dunion, J. P. and Velden, C. S.: The impact of the Saharan air layer on Atlantic tropical cyclone activity, B. Am. Meteorol. Soc., 85, 353, doi:10.1175/BAMS-85-3-353, 2004.

Fairall, C. W., Yang, M., Bariteau, L., Edson, J. B., Helmig, D., McGillis, W., Pezoa, S., Hare, J. E., Huebert, B., and Blomquist, B.: Implementation of the Coupled OceanAtmosphere Response Experiment flux algorithm with $\mathrm{CO} 2$, dimethyl sulfide, and $\mathrm{O}_{3}$, J. Geophys. Res-Atmos., 116, C00F09 doi:10.1029/2010JC006884, 2011.

Fast, J. D., Gustafson, W. I., Easter, R. C., Zaveri, R. A., Barnard, J. C., Chapman, E. G., Grell, G. A., and Peckham, S. E.: Evolution of ozone, particulates, and aerosol direct radiative forcing in the vicinity of Houston using a fully coupled meteorologychemistry-aerosol model, J. Geophys. Res-Atmos., 111, D21305, doi:10.1029/2005jd006721, 2006.

Fast, J., Aiken, A. C., Allan, J., Alexander, L., Campos, T., Canagaratna, M. R., Chapman, E., DeCarlo, P. F., de Foy, B., Gaffney, J., de Gouw, J., Doran, J. C., Emmons, L., Hodzic, A., Herndon, S. C., Huey, G., Jayne, J. T., Jimenez, J. L., Kleinman, L., Kuster, W., Marley, N., Russell, L., Ochoa, C., Onasch, T. B., Pekour, M., Song, C., Ulbrich, I. M., Warneke, C., WelshBon, D., Wiedinmyer, C., Worsnop, D. R., Yu, X.-Y., and Zaveri, R.: Evaluating simulated primary anthropogenic and biomass burning organic aerosols during MILAGRO: implications for assessing treatments of secondary organic aerosols, Atmos. Chem. Phys., 9, 6191-6215, doi:10.5194/acp-9-6191-2009, 2009.

Garreaud, R. D. and Munoz, R. C.: The low-level jet off the west coast of subtropical South America: Structure and variability, Mon. Weather Rev., 133, 2246-2261, 2005.

George, R. C. and Wood, R.: Subseasonal variability of low cloud radiative properties over the southeast Pacific Ocean, Atmos. Chem. Phys., 10, 4047-4063, doi:10.5194/acp-10-4047-2010, 2010.

Gong, S. L., Barrie, L. A., and Blanchet, J. P.: Modeling sea-salt aerosols in the atmosphere .1. Model development, J. Geophys. Res.-Atmos., 102, 3805-3818, 1997.

Grell, G. A., Peckham, S. E., Schmitz, R., McKeen, S. A., Frost, G., Skamarock, W. C., and Eder, B.: Fully coupled "online" chemistry within the WRF model, Atmos. Environ., 39, 6957-6975, doi:10.1016/j.atmosenv.2005.04.027, 2005.

Guenther, A., Karl, T., Harley, P., Wiedinmyer, C., Palmer, P. I., and Geron, C.: Estimates of global terrestrial isoprene emissions using MEGAN (Model of Emissions of Gases and Aerosols from Nature), Atmos. Chem. Phys., 6, 3181-3210, doi:10.5194/acp-63181-2006, 2006.

Gustafson, W. I., Chapman, E. G., Ghan, S. J., Easter, R. C., and Fast, J. D.: Impact on modeled cloud characteristics due to simplified treatment of uniform cloud condensation nuclei during NEAQS 2004, Geophys. Res. Lett., 34, L19809, doi:10.1029/2007g1030021, 2007.
Hawkins, L. N., Russell, L. M., Covert, D. S., Quinn, P. K., and Bates, T. S.: Carboxylic acids, sulfates, and organosulfates in processed continental organic aerosol over the southeast Pacific Ocean during VOCALS-REx 2008, J. Geophys. Res.-Atmos., 115, D13201, doi:10.1029/2009jd013276, 2010.

Hong, S. Y., Noh, Y., and Dudhia, J.: A new vertical diffusion package with an explicit treatment of entrainment processes, Mon. Weather Rev., 134, 2318-2341, 2006.

Huneeus, N., Gallardo, L., and Rutllant, J. A.: Offshore transport episodes of anthropogenic sulfur in northern Chile: Potential impact on the stratocumulus cloud deck, Geophys. Res. Lett., 33, L19819, doi:10.1029/2006g1026921, 2006.

Jiang, H. L., Feingold, G., and Cotton, W. R.: Simulations of aerosol-cloud-dynamical feedbacks resulting from entrainment of aerosol into the marine boundary layer during the Atlantic Stratocumulus Transition Experiment, J. Geophys. Res.-Atmos., 107, 4813, doi:10.1029/2001JD001502, 2002.

Jimenez, P. A., Dudhia, J., Gonzalez-Rouco, J. F., Navarro, J., Montavez, J. P., and Garcia-Bustamante, E.: A revised scheme for the WRF surface layer formation, Mon. Weather Rev., doi:10.1175/MWR-D-11-00056.1, in preparation, 2011.

Kleinman, L. I., Daum, P. H., Lee, Y.-N., Lewis, E. R., Sedlacek III, A. J., Senum, G. I., Springston, S. R., Wang, J., Hubbe, J., Jayne, J., Min, Q., Yum, S. S., and Allen, G.: Aerosol concentration and size distribution measured below, in, and above cloud from the DOE G-1 during VOCALS-REx, Atmos. Chem. Phys. Discuss., 11, 17289-17336, doi:10.5194/acpd-11-17289-2011, 2011.

Loeb, N. G., Kato, S., Loukachine, K., and Manalo-Smith, N.: Angular distribution models for top-of-atmosphere radiative flux estimation from the Clouds and the Earth's Radiant Energy System instrument on the Terra satellite, Part I: Methodology, J. Atmos. Ocean. Tech., 22, 338-351, 2005.

Matsui, T., Masunaga, H., Kreidenweis, S. M., Pielke, R. A., Tao, W. K., Chin, M., and Kaufman, Y. J.: Satellite-based assessment of marine low cloud variability associated with aerosol, atmospheric stability, and the diurnal cycle, J. Geophys. Res-Atmos., 111, D20202, doi:10.1029/2006jd008056, 2006.

Monahan, E. C., Spiel, D. E., and Davidson, K. L.: A model of marine aerosol generation via whitecaps and wave disruption, in: Oceanic Whitecaps, edited by: Niocail, E. C. M. a. G. M., Reidel, D., Norwell, 167-174, 1986.

Morrison, H., Curry, J. A., and Khvorostyanov, V. I.: A new doublemoment microphysics parameterization for application in cloud and climate models, Part I: Description, J. Atmos. Sci., 62, 1665$1677,2005$.

Morrison, H., Thompson, G., and Tatarskii, V.: Impact of Cloud Microphysics on the Development of Trailing Stratiform Precipitation in a Simulated Squall Line: Comparison of One- and Two-Moment Schemes, Mon. Weather Rev., 137, 991-1007, doi:10.1175/2008mwr2556.1, 2009.

Nightingale, P. D., Malin, G., Law, C. S., Watson, A. J., Liss, P. S., Liddicoat, M. I., Boutin, J., and Upstill-Goddard, R. C.: In situ evaluation of air-sea gas exchange parameterizations using novel conservative and volatile tracers, Global Biogeochem. Cy., 14, 373-387, 2000.

Painemal, D. and Zuidema, P.: Microphysical variability in southeast Pacific Stratocumulus clouds: synoptic conditions and radiative response, Atmos. Chem. Phys., 10, 6255-6269, doi:10.5194/acp-10-6255-2010, 2010. 
Qian, Y., Gustafson, W. I., Leung, L. R., and Ghan, S. J.: Effects of soot-induced snow albedo change on snowpack and hydrological cycle in western United States based on Weather Research and Forecasting chemistry and regional climate simulations, J. Geophys. Res-Atmos., 114, D03108, doi:10.1029/2008jd011039, 2009.

Rahn, D. A. and Garreaud, R.: Marine boundary layer over the subtropical southeast Pacific during VOCALS-REx - Part 1: Mean structure and diurnal cycle, Atmos. Chem. Phys., 10, 4491-4506, doi:10.5194/acp-10-4491-2010, 2010.

Remer, L. A., Kleidman, R. G., Levy, R. C., Kaufman, Y. J., Tanre, D., Mattoo, S., Martins, J. V., Ichoku, C., Koren, I., Yu, H. B., and Holben, B. N.: Global aerosol climatology from the MODIS satellite sensors, J. Geophys. Res-Atmos., 113, D14S07, doi:10.1029/2007jd009661, 2008.

Rogers, R. R. and Yau, M. K.: A short course in cloud physics, 125-126, 1989.

Russell, L. M., Hawkins, L. N., Frossard, A. A., Quinn, P. K., and Bates, T. S.: Carbohydrate-like composition of submicron atmospheric particles and their production from ocean bubble bursting, P. Natl. Acad. Sci. USA, 107, 6652-6657, doi:10.1073/pnas.0908905107, 2010.

Shaw, W. J., Allwine, K. J., Fritz, B. G., Rutz, F. C., Rishel, J. P., and Chapman, E. G.: Evaluation of the wind erosion module in DUSTRAN, Atmos. Environ., 42, 1907-1921, doi:10.1016/j.atmosenv.2007.11.022, 2008.

Shrivastava, M., Fast, J., Easter, R., Gustafson Jr., W. I., Zaveri, R. A., Jimenez, J. L., Saide, P., and Hodzic, A.: Modeling organic aerosols in a megacity: comparison of simple and complex representations of the volatility basis set approach, Atmos. Chem. Phys., 11, 6639-6662, doi:10.5194/acp-11-6639-2011, 2011.

Skamarock, W. C.: Evaluating mesoscale NWP models using kinetic energy spectra, Mon. Weather Rev., 132, 3019-3032, 2004.

Stevens, B. and Feingold, G.: Untangling aerosol effects on clouds and precipitation in a buffered system, Nature, 461, 607-613, doi:10.1038/nature08281, 2009.

Stevens, B., Vali, G., Comstock, K., Wood, R., van Zanten, M. C., Austin, P. H., Bretherton, C. S., and Lenschow, D. H.: Pockets of open cells and drizzle in marine stratocumulus, B. Am. Meteorol. Soc., 86, 51, doi:10.1175/BAMS-86-1-51, 2005.

Toniazzo, T., Abel, S. J., Wood, R., Mechoso, C. R., Allen, G., and Shaffrey, L. C.: Large-scale and synoptic meteorology in the south-east Pacific during the observations campaign VOCALSREx in austral Spring 2008, Atmos. Chem. Phys., 11, 497705009, doi:10.5194/acp-11-4977-2011, 2011.

Twomey, S.: Influence of Pollution on Shortwave Albedo of Clouds, J. Atmos. Sci., 34, 1149-1152, 1977.

Wang, H. and Feingold, G.: Modeling Mesoscale Cellular Structures and Drizzle in Marine Stratocumulus. Part II: The Microphysics and Dynamics of the Boundary Region between Open and Closed Cells, J. Atmos. Sci., 66, 3257-3275, doi:10.1175/2009jas3120.1, 2009a.

Wang, H. and Feingold, G.: Modeling Mesoscale Cellular Structures and Drizzle in Marine Stratocumulus, Part I: Impact of Drizzle on the Formation and Evolution of Open Cells, J. Atmos. Sci., 66, 3237-3256, doi:10.1175/2009jas3022.1, 2009b.

Wang, H., Skamarock, W. C., and Feingold, G.: Evaluation of Scalar Advection Schemes in the Advanced Research WRF Model Using Large-Eddy Simulations of Aerosol-
Cloud Interactions, Mon. Weather Rev., 137, 2547-2558, doi:10.1175/2009mwr2820.1, 2009.

Wiedinmyer, C., Akagi, S. K., Yokelson, R. J., Emmons, L. K., AlSaadi, J. A., Orlando, J. J., and Soja, A. J.: The Fire INventory from NCAR (FINN): a high resolution global model to estimate the emissions from open burning, Geosci. Model Dev., 4, 625641, doi:10.5194/gmd-4-625-2011, 2011.

Wood, R. and Bretherton, C. S.: Boundary layer depth, entrainment, and decoupling in the cloud-capped subtropical and tropical marine boundary layer, J. Climate, 17, 3576-3588, 2004.

Wood, R., Bretherton, C. S., Leon, D., Clarke, A. D., Zuidema, P., Allen, G., and Coe, H.: An aircraft case study of the spatial transition from closed to open mesoscale cellular convection over the Southeast Pacific, Atmos. Chem. Phys., 11, 2341-2370, doi:10.5194/acp-11-2341-2011, 2011a.

Wood, R., Mechoso, C. R., Bretherton, C. S., Weller, R. A., Huebert, B., Straneo, F., Albrecht, B. A., Coe, H., Allen, G., Vaughan, G., Daum, P., Fairall, C., Chand, D., Gallardo Klenner, L., Garreaud, R., Grados, C., Covert, D. S., Bates, T. S., Krejci, R., Russell, L. M., de Szoeke, S., Brewer, A., Yuter, S. E., Springston, S. R., Chaigneau, A., Toniazzo, T., Minnis, P., Palikonda, R., Abel, S. J., Brown, W. O. J., Williams, S., Fochesatto, J., Brioude, J., and Bower, K. N.: The VAMOS Ocean-Cloud-Atmosphere-Land Study Regional Experiment (VOCALS-REx): goals, platforms, and field operations, Atmos. Chem. Phys., 11, 627-654, doi:10.5194/acp-11-6272011, $2011 b$.

Wyant, M. C., Wood, R., Bretherton, C. S., Mechoso, C. R., Bacmeister, J., Balmaseda, M. A., Barrett, B., Codron, F., Earnshaw, P., Fast, J., Hannay, C., Kaiser, J. W., Kitagawa, H., Klein, S. A., Köhler, M., Manganello, J., Pan, H.-L., Sun, F., Wang, S., and Wang, Y.: The PreVOCA experiment: modeling the lower troposphere in the Southeast Pacific, Atmos. Chem. Phys., 10, 4757-4774, doi:10.5194/acp-10-4757-2010, 2010.

Yang, M., Blomquist, B. W., and Huebert, B. J.: Constraining the concentration of the hydroxyl radical in a stratocumulus-topped marine boundary layer from sea-to-air eddy covariance flux measurements of dimethylsulfide, Atmos. Chem. Phys., 9, 92259236, doi:10.5194/acp-9-9225-2009, 2009.

Yang, M., Huebert, B. J., Blomquist, B. W., Howell, S. G., Shank, L. M., McNaughton, C. S., Clarke, A. D., Hawkins, L. N., Russell, L. M., Covert, D. S., Coffman, D. J., Bates, T. S., Quinn, P. K., Zagorac, N., Bandy, A. R., de Szoeke, S. P., Zuidema, P. D., Tucker, S. C., Brewer, W. A., Benedict, K. B., and Collett, J. L.: Atmospheric sulfur cycling in the southeastern Pacific longitudinal distribution, vertical profile, and diel variability observed during VOCALS-REx, Atmos. Chem. Phys., 11, 50795097, doi:10.5194/acp-11-5079-2011, 2011.

Zaveri, R. A., Easter, R. C., Fast, J. D., and Peters, L. K.: Model for Simulating Aerosol Interactions and Chemistry (MOSAIC), J. Geophys. Res.-Atmos., 113, D13204, doi:10.1029/2007jd008782, 2008.

Zhang, Y., Olsen, S. C., and Dubey, M. K.: WRF/Chem simulated springtime impact of rising Asian emissions on air quality over the US, Atmos. Environ., 44, 2799-2812, doi:10.1016/j.atmosenv.2010.05.003, 2010.

Zhao, C., Liu, X., Leung, L. R., Johnson, B., McFarlane, S. A., Gustafson Jr., W. I., Fast, J. D., and Easter, R.: The spatial distribution of mineral dust and its shortwave radiative forcing 
over North Africa: modeling sensitivities to dust emissions and aerosol size treatments, Atmos. Chem. Phys., 10, 8821-8838, doi:10.5194/acp-10-8821-2010, 2010.
Zuidema, P., Painemal, D., de Szoeke, S., and Fairall, C.: Stratocumulus Cloud-Top Height Estimates and Their Climatic Implications, J. Climate, 22, 4652-4666, doi:10.1175/2009jcli2708.1, 2009. 